\title{
Microbiome dynamics in the tissue and mucus of acroporid corals differ in relation to host and environmental parameters
}

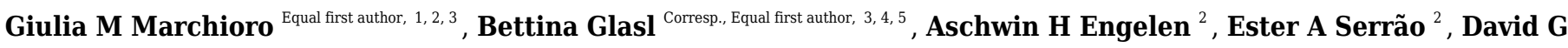 \\ Bourne $^{3,4,5}$, Nicole S Webster ${ }^{3,4,6}$, Pedro R Frade ${ }^{2}$ \\ ${ }^{1}$ University of Algarve, Faro, Portugal \\ 2 CCMAR - Centre of Marine Sciences, University of Algarve, Faro, Portugal \\ 3 AIMS@JCU, Townsville, Queensland, Australia \\ 4 Australian Institute of Marine Science, Townsville, Queensland, Australia \\ ${ }^{5}$ College of Science and Engineering, James Cook University, Townsville, Australia \\ ${ }^{6}$ Australian Centre for Ecogenomics, University of Queensland, Brisbane, Queensland, Australia \\ Corresponding Author: Bettina Glasl \\ Email address: b.glasl@aims.gov.au
}

Corals are associated with diverse microbial assemblages; however, the spatial-temporal dynamics of intra-species microbial interactions are poorly understood. The coralassociated microbial community varies substantially between tissue and mucus microhabitats, however, the factors controlling the occurrence, abundance, and distribution of microbial taxa over time have rarely been explored for different compartments simultaneously. Here, we test 1 ) differentiation in microbiome diversity and composition between coral compartments (surface mucus and tissue) of two Acropora hosts ( $A$. tenuis and $A$. millepora) common along inshore reefs of the Great Barrier Reef, as well as 2 ) the potential linkage between shifts in individual coral microbiome families and underlying host and environmental parameters. Amplicon based 16S ribosomal RNA gene sequencing of 136 samples collected over 14 months, revealed significant differences in bacterial richness, diversity and community structure among mucus, tissue and the surrounding seawater. Seawater samples were dominated by members of the Synechococcaceae and Pelagibacteraceae bacterial families. The mucus microbiome of Acropora spp. was dominated by members of Flavobacteriaceae, Synechococcaceae and Rhodobacteraceae and the tissue was dominated by Endozoicimonaceae. Mucus microbiome in both Acropora species was primarily correlated with seawater parameters including levels of chlorophyll a, ammonium, particulate organic carbon and the sum of nitrate and nitrite. In contrast, the correlation of the tissue microbiome to the measured environmental (i.e. seawater parameters) and host health physiological factors differed between host species, suggesting host-specific modulation of the tissue-associated microbiome to intrinsic and extrinsic factors. Furthermore, the correlation between 
individual coral microbiome members and environmental factors provides novel insights into coral microbiome-by-environment dynamics and hence has potential implications for current reef restoration and management efforts (e.g. microbial monitoring / observatory programs). 


\section{Microbiome dynamics in the tissue and mucus of}

2 acroporid corals differ in relation to host and

\section{3 environmental parameters}

4

5 Giulia M. Marchioro ${ }^{*}, 1,2,3$, Bettina Glasl ${ }^{*}, 3,4,5$, Aschwin H. Engelen ${ }^{2}$, Ester A. Serrão ${ }^{2}$, David G.

6 Bourne $^{3,4,5}$, Nicole S. Webster ${ }^{3,4,6}$, Pedro R. Frade ${ }^{2}$

7

8

$9 *$ these authors contributed equally to the study

$10{ }^{1}$ University of Algarve, Faro, Portugal

$11{ }^{2}$ CCMAR-Centre of Marine Sciences, University of Algarve, Faro, Portugal

123 AIMS@JCU, Townsville, Queensland, Australia

$13{ }^{4}$ Australian Institute of Marine Science, Townsville, Queensland, Australia

$14{ }^{5}$ College of Science and Engineering, James Cook University, Townsville, Queensland,

15 Australia

${ }^{6}$ Australian Centre for Ecogenomics, University of Queensland, Brisbane, Queensland, Australia

18 Corresponding Author:

19 Bettina Glasl

20 Australian Institute of Marine Science, Townsville, Queensland, Australia

21 Email address: b.glas1@aims.gov.au 


\section{Abstract}

23 Corals are associated with diverse microbial assemblages; however, the spatial-temporal

24 dynamics of intra-species microbial interactions are poorly understood. The coral-associated

25 microbial community varies substantially between tissue and mucus microhabitats, however, the

26 factors controlling the occurrence, abundance, and distribution of microbial taxa over time have

27 rarely been explored for different compartments simultaneously. Here, we test 1) differentiation

28 in microbiome diversity and composition between coral compartments (surface mucus and

29 tissue) of two Acropora hosts (A. tenuis and A. millepora) common along inshore reefs of the

30 Great Barrier Reef, as well as 2) the potential linkage between shifts in individual coral

31 microbiome families and underlying host and environmental parameters. Amplicon based $16 \mathrm{~S}$

32 ribosomal RNA gene sequencing of 136 samples collected over 14 months, revealed significant

33 differences in bacterial richness, diversity and community structure among mucus, tissue and the

34 surrounding seawater. Seawater samples were dominated by members of the Synechococcaceae

35 and Pelagibacteraceae bacterial families. The mucus microbiome of Acropora spp. was

36 dominated by members of Flavobacteriaceae, Synechococcaceae and Rhodobacteraceae and the

37 tissue was dominated by Endozoicimonaceae. Mucus microbiome in both Acropora species was

38 primarily correlated with seawater parameters including levels of chlorophyll $a$, ammonium,

39 particulate organic carbon and the sum of nitrate and nitrite. In contrast, the correlation of the

40 tissue microbiome to the measured environmental (i.e. seawater parameters) and host health

41 physiological factors differed between host species, suggesting host-specific modulation of the

42 tissue-associated microbiome to intrinsic and extrinsic factors. Furthermore, the correlation

43 between individual coral microbiome members and environmental factors provides novel

44 insights into coral microbiome-by-environment dynamics and hence has potential implications

45 for current reef restoration and management efforts (e.g. microbial monitoring / observatory

46 programs).

47

\section{Introduction}

49 Coral microbiomes include the well-characterized endosymbiotic dinoflagellates of the family

50 Symbiodiniaceae, and a vast diversity of bacteria and archaea (Bourne, Morrow \& Webster, 51 2016; Frade et al., 2016a; Rowher et al., 2002). The microbiome has a fundamental role in the

52 health and stability of the coral holobiont; it recycles nutrients, removes waste products and 
53 defends against pathogens (Lema, Willis \& Bourne, 2012; Morris et al., 2011; Rädecker et al., 54 2015; Rosado et al., 2019). The coral microbiome is influenced by a variety of intrinsic and

55

56

57 58

59

60

61

62

63

64

65

66

67

68

69

70

71

72

73

74

75

76

77

78

79

80

81

82 83 extrinsic factors. Coral microbiomes are host species-specific and were thought to remain relatively stable over space and time (Frias-Lopez et al., 2002; Rowher et al., 2002). However, recent studies have proposed that spatial-temporal factors such as environmental parameters (Chen et al., 2011), depth (Glasl et al., 2017), geography (Hong et al., 2009; Littman et al., 2009a), seasonality (Ceh, van Keulen \& Bourne, 2011; Chen et al., 2011; Hong et al., 2009; Koren \& Rosenberg, 2006), coastal pollution (Klaus et al., 2007), and the physiological status of the host (Grottoli et al., 2018; Littman, Willis \& Bourne, 2009b) can also influence the occurrence and relative abundance of microbial taxa. For instance, Li et al. (2015) reported a dynamic relationship between the community structure of coral-associated bacteria and the seasonal variation in environmental parameters such as dissolved oxygen and rainfall. Glasl et al. (2019a) showed that although host-associated microbiomes were five-times less responsive to the environment compared to the seawater microbiome, they were still affected by environmental factors (e.g. temperature, turbidity, and nutrient concentration).

The coral provides different microhabitats for its microbial associates, including the surface mucus layer, coral tissue, skeleton and gastrovascular cavity, each differing in microbial richness, diversity and community structure, often assessed through alpha- and beta-diversity metrics (Agostini et al., 2012; Engelen et al., 2018; Pollock et al., 2018; Sweet, Croquer \& Bythell, 2011). Each microhabitat has a unique set of biochemical features and harbors a specific microbial community (Engelen et al., 2018; Pollock et al., 2018; Sweet, Croquer \& Bythell, 2011). Hence, revealing microhabitat-specific host-microbiome associations and their specific sensitivities to environmental fluctuations is crucial to our understanding of coral holobionts. For example, the coral surface mucus layer is a polysaccharide-protein-lipid complex that provides an interface between the coral epithelium and the surrounding seawater (Brown \& Bythell, 2005). Here microbes take advantage of a nutrient-rich medium and particular microbiome members found in the coral mucus overlap with both the tissue and the seawater microbial communities (Bourne \& Munn, 2005; Brown \& Bythell, 2005; Glasl, Herndl \& Frade, 2016; Sweet, Croquer \& Bythell, 2011). In contrast to the extracellular polymeric nature of the surface mucus layer, the coral tissue consists of two distinct layers (epidermis and gastrodermis) and a connective-tissue layer, the mesoglea (Muller-Parker, D’Elia \& Cook, 2015). The coral tissue

Peer] reviewing PDF | (2020:02:45510:2:0:NEW 6 Jul 2020) 
84 harbors photosymbiotic dinoflagellates (family Symbiodiniaceae), that can provide up to 100\%

85 of energy required by their coral host (Muller-Parker, D’Elia \& Cook, 2015). The

86 Symbiodiniaceae community has been shown to vary in tandem with the bacterial community in

87 early life stages of corals (Quigley et al., 2019) and this may be caused by the release of complex

88 organic molecules such as the organosulfur compound dimethylsulfoniopropionate (DMSP;

89 Bourne et al., 2013; Frade et al., 2016b). The coral tissue microbiome is mostly represented by

90 bacteria belonging to the phyla Proteobacteria and Actinobacteria. For example, the

91 gammaproteobacterial Endozoicomonas are abundant in the coral's endodermal tissue and are

92 often considered 'true' coral symbionts (Bayer et al., 2013; Glasl et al., 2019b; Neave et al.,

93 2016, 2017). When compared to the surface mucus layer, the microbial community in the tissue

94 is significantly less dense and diverse (Bourne \& Munn, 2005; Koren \& Rosenberg, 2006), likely

95 attributed to the more spatially stable and host controlled environment (Bourne \& Munn, 2005),

96 although divergent evidence suggests the mucus is less diverse than the tissue (Pollock et al.,

97 2018). Furthermore, tissue-associated bacterial communities form aggregations within the coral

98 cell layers, also referred to as coral-associated microbial aggregates (CAMAs), and are often co-

99 localized near algal symbiont cells, highlighting potential metabolic interactions between

100 symbionts (Wada et al., 2019).

101 In this study, we test the hypotheses that different coral compartments (surface mucus

102 layer and tissue) of Acropora spp. harbor distinct microbial communities and that different

103 intrinsic and extrinsic factors explain microbiome dynamics within these compartments.

104 Furthermore, we aim to identify significant correlations of individual bacterial families

105 associated with coral tissue and mucus with host-physiological and seawater parameters.

106

107 Materials \& Methods

108 Sample collection

109 Samples of Acropora millepora (Ehrenberg, 1834), Acropora tenuis (Dana, 1846) and seawater

110 were collected monthly, at Geoffrey Bay (Magnetic Island) in the Great Barrier Reef

111 (Supplementary Figure S1), between February 2016 and March 2017, for amplicon based 16S

112 ribosomal RNA (rRNA) gene sequencing along with environmental metadata. All samples were

113 collected under the permit G16/38348.1 issued by the Great Barrier Reef Marine Park Authority. 
114

115

116

117

118

119

120

121

122

123

124

125

126

127

128

129

130

131

132

133

134

135

136

137

138

139

140

141

142

143

144

Samples ( $n=3$ per sample type and per sampling event) for molecular analysis were collected as part of the Australian Microbiome Initiative and the sample procedure has previously been outlined by Glasl et al. (2019a). In brief, coral nubbins (approximately $5 \mathrm{~cm}$ tall) of both Acropora species were collected, rinsed with $0.2 \mu \mathrm{m}$ filter-sterilized seawater and placed into cryogenic vials. Coral mucus from the same specimens was collected with sterile cotton swabs as previously described by Glasl, Herndl \& Frade (2016). Seawater samples for molecular analysis were collected in sterile collapsible bags, pre-filtered through a $50 \mu \mathrm{m}$ filter mesh to remove large particles, and subsequently filtered onto a $0.2 \mu \mathrm{m}$ Sterivex filter (Millipore). Coral nubbins, mucus swabs and Sterivex filters were immediately snap frozen in liquid nitrogen after collection and stored at $-80^{\circ} \mathrm{C}$ until further processing. To acquire environmental information, water and sediment samples were collected in duplicate for each sampling event as described in Glasl et al. (2019a) and further analyzed according to the standard procedures of Australian Institute of Marine Science (Devlin \& Lourey, 2000). The environmental information processed includes common reef water quality measures such as salinity, particulate organic carbon, total suspended solids, concentrations of chlorophyll $a$, ammonium, the sum of nitrite and nitrate, particulate nitrogen, nitrite, total nitrogen, non-purgeable organic carbon, non-purgeable inorganic carbon, phosphate and silica as well as total organic carbon in the sediment, total organic nitrogen in the sediment and grainsize percentage of sediments $<0.63 \mu \mathrm{m}$, between 0.63 $\mu \mathrm{m}$ and $2 \mathrm{~mm}$, and $>2 \mathrm{~mm}$. Seawater temperatures and daylight hours were obtained from AIMS long-term monitoring temperature records (http://eatlas.org.au).

\section{Sample preparation and genetic assays}

Frozen coral tissue was airbrushed into a ziploc bag with phosphate-buffered saline (PBS) solution added until all tissue was removed from the skeletal fragment (PBS volume noted). The resulting tissue slurry was homogenized for $1 \mathrm{~min}$ at 12,500 rpm using a hand-held tissue homogenizer (Heidolph Silent Crusher M), pelleted (10 min at 16,000 rcf) and snap frozen in liquid nitrogen. DNA from the tissue and mucus samples was extracted using the DNeasy PowerBiofilm kit (QIAGEN). DNA extracts were sent on dry ice to the Ramaciotti Centre for Genomics (Sydney, Australia) for sequencing. The bacterial 16S rRNA gene was sequenced using the 27F (Lane, 1991) and 519R (Turner et al., 1999) primers on the Illumina MiSeq platform using a dual indexed 2 x 300 bp paired-end approach. Primers pairs were selected to 
145 warrant comparability across datasets of the Australian Microbiome Initiative

146 (https://www.australianmicrobiome.com).

147

148 Sequence analysis

149 Sequencing data were analyzed as single nucleotide variants following the standardized platform 150 of the Australian Microbiome Initiative (Brown et al., 2018). In brief, paired-end reads were 151 merged using FLASH software (Magoc \& Salzberg, 2011) and FASTA formatted sequences 152 were extracted from FASTQ files. Sequences $<400 \mathrm{bp}$ in length, and / or containing one or more 153 N's, or homopolymer runs of $>8$ bp were removed with MOTHUR (v1.34.1; Schloss et al., 154 2009). Sequences were de-replicated and ordered by abundance using USEARCH (64 bit 155 v10.0.240; Edgar, 2010). Sequences with less than 4 representatives and Chimeras were 156 removed, and the quality-filtered sequences were mapped to chimera-free zero-radius operational 157 taxonomic units (zOTUs). A table containing the samples and their read abundances was created 158 and the zOTUs were taxonomically classified with SILVA v132 database (Yilmaz et al., 2014) 159 using MOTHUR's implementation of the Wang classifier (Wang et al., 2007) and a 60\% 160 Bayesian probability cut-off. This sequencing dataset has already been used in a previous 161 contribution by the research group (Glasl et al., 2019a), but in the current study it is analyzed 162 from a different perspective aiming at comparing temporal microbiome dynamics between two 163 distinct coral compartments.

164 Chloroplasts and mitochondria derived reads were removed from the dataset and 165 remaining data was rarefied to a sequencing depth of 3,500 reads per sample in R (R Core Team, 166 2015) using subset_taxa () function in the phyloseq package (McMurdie \& Holmes, 2013). Read 167 counts per sample were transformed into relative abundances.

\section{Coral holobiont photopigment quantification}

170 Photopigment (chlorophyll $a$ ) concentrations in the tissue of corals were quantified using a 171 spectrophotometric approach (Glasl et al., 2019b). Tissue pellets were thawed on ice to avoid 172 sample degradation and resuspended in $1 \mathrm{ml}$ of $90 \%$ ethanol. Samples were sonicated for $1 \mathrm{~min}$ 173 and centrifuged for $5 \mathrm{~min}$ at 10,000 rcf. Subsequently, $700 \mu \mathrm{l}$ of the supernatant was removed 174 and transferred to a new tube. The resuspension, sonication and centrifugation were repeated on 175 the remainder of the pellet. The supernatant was recovered again, combined with the previous 
176 extraction and mixed by inversion. Sample extract and 90\% ethanol (blank read) were loaded in

177 triplicate (200 $\mu \mathrm{l}$ each) to a 96-well plate and the absorbance was recorded at 470, 632, 649, 665,

178696 and $750 \mathrm{~nm}$ in a Cytation 3 multi-mode microplate reader (BioTek, Winooski, USA) and

179 analyzed using the software Gen5 (BioTek, Winooski, USA). Blank corrected absorbance

180 measures were used to calculate chlorophyll $a$ concentrations (Supplementary Equation S1).

181

182 Coral protein quantification

183 Soluble protein concentrations of coral tissue samples were quantified using a colorimetric

184 protein assay kit (Pierce BCA Protein Assay Kit; Glasl et al., 2019b). Tissue pellets were thawed 185 on ice and resuspended in $1 \mathrm{ml}$ PBS. The resuspension $(25 \mu \mathrm{l})$ was added to $200 \mu \mathrm{l}$ of working 186 reagent from the kit in a 96-well plate. The plate was mixed thoroughly on a plate shaker for 30 187 seconds and then incubated at $37^{\circ} \mathrm{C}$ for $30 \mathrm{~min}$. The plate was cooled down at room temperature.

188 The absorbance was measured at $563 \mathrm{~nm}$ in a Cytation 3 multi-mode microplate reader (BioTek, 189 Winooski, USA) and analyzed using the software Gen5 (BioTek, Winooski, USA).

190 Measurements of the standards and samples were blank corrected to remove background 191 absorbance. For each plate, a protein standard curve was obtained using bovine serum albumin 192 (BSA) solution at concentrations between 25 and 2,000 $\mu \mathrm{g} \mathrm{ml}^{-1}$.

193

194 Symbiodiniaceae cell counting

195 To determine cell numbers of Symbiodiniaceae in the coral tissue, the tissue pellet was thawed 196 on ice, resuspended in $1 \mathrm{ml}$ of $0.2 \mu \mathrm{l}$ filtered seawater and fixed in $2 \%$ formaldehyde (final 197 concentration) to preserve the symbiont cells. The solution was passed through a syringe needle 198 to reduce cell agglomeration and diminish the bias from cell clumps. Samples were then mixed 199 for $1 \mathrm{~min}$ and $10 \mu \mathrm{l}$ of the homogenate was loaded onto a Neubauer haemocytometer $(0.100 \mathrm{~mm}$ 200 depth). Symbiodiniaceae cells were counted under 40 x magnification with an Olympus CX31 201 light microscope. In total, six independent haemocytometer loadings ( 24 squares each with $0.1 \mu l$ 202 volume) were used per sample to ensure robustness of density determinations. 203

\section{Statistical analyses}

205 Statistical analyses were performed using RStudio (v1.1.463). Analyses of microbial 206 communities were performed on rarefied relative abundance data at zOTU level. zOTU richness 
207 and Shannon-Weaver diversity were compared across host compartments, host species and 208 reference seawater samples using non-parametric Analysis of Variance (Kruskal-Wallis test 209 using function kruskal.test), followed by Dunn's test for multiple comparisons (function 210 dunn.test). All p-values were adjusted using the Benjamini-Hochberg multiple comparison 211 correction method to decrease the false discovery rate (Benjamini \& Hochberg, 1995). A Venn 212 diagram was constructed to describe the shared and unique zOTUs among mucus, tissue and 213 seawater microbiomes using VennDiagram package (Chen \& Boutros, 2011) and visualized 214 using eulerr package (Larsson, 2020). Non-Metric Multidimensional Scaling (NMDS) was used 215 to illustrate the microbial community structure among host species and host compartments based 216 on Bray-Curtis dissimilarities (phyloseq package, McMurdie \& Holmes, 2013). Permutational 217 Multivariate Analysis of Variance (PERMANOVA, 999 permutations) was used to test for 218 differences in microbial structure between host species and host compartments using the adonis2 219 function of the vegan package (Oksanen et al., 2013).

Physiological variables were normalized (i.e., chlorophyll $a$ normalized to protein content, 221 chlorophyll $a$ normalized to Symbiodiniaceae numbers, Symbiodiniaceae density normalized to 222 protein content) following common procedures in coral physiology studies (Frade et al., 2008, Iglesias-Prieto \& Trench, 1997). Due to fragmentation of the collected coral branches, coral surface area could not be measured. Environmental and physiological variables were 225 standardized and checked for collinearity using the Pearson correlation coefficient. Redundant 226 variables based on Pearson's correlation ( $>0.7$ or $<-0.7$; Dormann et al., 2013) were removed from the analysis. Non-correlated variables were then used in a Bray-Curtis distance-based Redundancy Analysis (db-RDA), which quantifies the impact of the explanatory variables on the microbiome (dis)similarities (Legendre \& Anderson, 1999). zOTU relative abundance, environmental and physiological metadata were used for db-RDA using the phyloseq package 231 (McMurdie \& Holmes, 2013). The analysis tests the statistical relationship between microbial 232 community composition and the environmental/physiological variables for each coral compartment and host species combination. A model selection tool (ordiR2step function in the vegan package, sensu Blanchet, Legendre \& Borcard, 2008) was performed to select the best dbRDA model (i.e., the best explanatory variables) for variation in microbiome composition of each coral compartment (mucus and tissue) in each host species (Johnson \& Omland, 2004). The 237 significance of each explanatory variable was confirmed with an ANOVA-like permutational test 
238 (function permutest") for dbRDA. The explanatory value (in \%) of significant explanatory 239 variables (e.g. environmental and physiological parameters) on each microbiome was assessed 240 with Variation Partitioning Analysis of the vegan package (Oksanen et al., 2013). A correlation 241 matrix (based on the default Pearson correlation) between the relative abundance of the 20 most 242 abundant microbial families and significant environmental variables was generated using the $\mathrm{R}$ 243 package MicrobiomSeq (Ssekagiri, Sloan \& Ijaz, 2017), for which p-values were adjusted using 244 the Benjamini-Hochberg multiple comparison correction (Benjamini \& Hochberg, 1995).

245

246 Results

247 Composition of coral tissue and mucus microbiomes

248 The bacterial 16S rRNA genes of 136 samples, including coral tissue ( $\mathrm{n}=24$ for A. millepora; $\mathrm{n}$ $249=30$ for A. tenuis), coral mucus layer ( $\mathrm{n}=24$ for A. millepora; $\mathrm{n}=28$ for A. tenuis) and seawater $250(\mathrm{n}=30$; used as reference samples) were sequenced and 12,051 zOTUs identified at single 251 nucleotide variants.

252 zOTU richness differed significantly among mucus, tissue and seawater microbiomes 253 (Kruskal-Wallis $\mathrm{Chi}^{2}{ }_{(2,133)}=57.74, \mathrm{p}=2.89 \times 10^{-13}$ ), but not between seasons (see 254 Supplementary Table S1). Coral zOTU richness differed between species (A. millepora vs A. 255 tenuis; Kruskal-Wallis $\left.C h i^{2}{ }_{(1,134)}=12.23, \mathrm{p}=0.00047\right)$. Seawater harbored the richest microbial 256 community (558 zOTU \pm 54.6 ), followed by the mucus (A. millepora, $220 \mathrm{zOTU} \pm 188 ; A$. 257 tenuis $511 \mathrm{zOTU} \pm 234$ ) and tissue (A. millepora, $125 \mathrm{zOTU} \pm 31.6$; A. tenuis, $173 \mathrm{zOTU} \pm 146$; 258 Supplementary Table S1). Alpha diversity based on Shannon Index also differed significantly 259 among microbiomes from mucus, tissue and seawater (Kruskal-Wallis $\mathrm{Chi}^{2}{ }_{(2,133)}=53.37, \mathrm{p}=$ $2602.57 \times 10^{-12}$ ), but not between seasons (see Supplementary Table S1). Coral zOTU Shannon 261 differed between species (A. millepora vs A. tenuis; Kruskal-Wallis $C h i^{2}{ }_{(1,134)}=6.002, \mathrm{p}=$ 262 0.01429). Alpha diversity measures of mucus samples were not significantly different (Shannon 263 Index: A. millepora, $4.18 \pm 0.83$; A. tenuis, $5.15 \pm 0.69$ ) from seawater samples (Shannon Index: $2644.40 \pm 0.209$; Supplementary Table S1). In contrast, the tissue microbiome was dramatically 265 different from the mucus and seawater microbiomes and harbored the lowest microbial diversity 266 (Shannon Index: A. millepora, $3.35 \pm 0.63$; A. tenuis, $3.54 \pm 0.84$ ). Sequences affiliated to the phyla Proteobacteria dominated the microbial community of 268 all samples (average relative abundance \pm SD; mucus: $44.1 \pm 11.5 \%$; tissue: $62.8 \pm 2 \%$; 
269 seawater: $39.6 \pm 3.1$ ), followed in dominance by Bacteroidetes (mucus: $27.5 \pm 13.0 \%$; tissue: 9.6 $270 \pm 10.9 \%$; seawater: $12.0 \pm 11.4 \%$ ) and Cyanobacteria (mucus: $14.4 \pm 9.0 \%$; tissue: $9.8 \pm 11.0 \%$; 271 seawater: $38.5 \pm 4.0 \%$ ). Mucus microbiomes for both Acropora species (Figure 1) were 272 characterized mostly by members of the family Flavobacteriaceae (average relative abundance \pm 273 SD; for A. tenuis: $17.3 \pm 9.1 \%$; A. millepora: $17.3 \pm 12.7 \%$ ), Synechococcaceae (A. tenuis: 12.3 $274 \pm 7.8 \%$; A. millepora: $13.1 \pm 10.2 \%$ ) and Rhodobacteraceae (A. tenuis: $5.7 \pm 3.0 \%$; A. millepora: $2756.4 \pm 6.4 \%$; Figure 1). In contrast, the Endozoicimonaceae family dominated the tissue 276 microbiome (A. tenuis: $43.2 \pm 31.7 \%$; A. millepora: $20.5 \pm 19.7 \%$ ), with additional 277 representation of Flavobacteriaceae (A. tenuis: $7.9 \pm 9.6 \%$; A. millepora: $7.2 \pm 9.6 \%$ ),

278 Synechococcaceae (A. tenuis: $5.5 \pm 6.8 \%$; A. millepora: $12.3 \pm 14.5 \%)$ and Rhodobacteraceae $(A$. 279 tenuis: $6.5 \pm 10.4 \%$; A. millepora: $5.3 \pm 8.5 \%$; Figure 1) families. Seawater samples were mostly 280 characterized by members of Synechococcaceae $(36.6 \pm 3.9 \%)$ and Pelagibacteraceae (18.6 \pm $2814.9 \%)$, but also by Rhodobacteraceae $(8.6 \pm 4.8 \%)$ and Flavobacteriaceae $(8.0 \pm 2.6 \%$; Figure 1). 282 Tissue and mucus microbiomes exclusively shared 1,193 zOTU (9.9\%), mucus and seawater 283 microbiomes exclusively shared 1,458 zOTU (12.1\%), whereas the tissue and seawater 284 microbiome shared only 66 zOTU (0.6\%; Figure 2$)$.

285 Microbial community composition (beta-diversity) significantly differed among mucus, 286 tissue and seawater (Figure 3; PERMANOVA, pseudo- $F_{(2,126)}=14.53, \mathrm{p}=0.001$ ), between 287 Acropora species (PERMANOVA, pseudo- $F_{(1,126)}=4.42, \mathrm{p}=0.001$ ), and between seasons 288 (PERMANOVA, pseudo- $\left.F_{(1,126)}=1.90, \mathrm{p}=0.011\right)$. Interaction between species and 289 compartment was also significant (PERMANOVA, pseudo- $F_{(1,126)}=3.07, \mathrm{p}=0.002$; other 290 interactions were not significant; Supplementary Table S2).

291

292 Explanatory variables of coral tissue and mucus microbiomes

293 Physiological parameters of the tissue (i.e., chlorophyll $a$ normalized to protein content, 294 chlorophyll $a$ normalized to Symbiodiniaceae numbers, Symbiodiniaceae density normalized to 295 protein content) remained stable between host species.

296 Out of a total of 20 environmental variables measured for seawater and sediment, 6 297 variables were non-mutually collinear and were thus included in the db-RDA analysis. Selected 298 variables were salinity, concentration of particulate organic carbon (POC), total suspended solids 
299 (TSS), chlorophyll $a(\mathrm{Chl} a)$, ammonium $\left(\mathrm{NH}_{4}^{+}\right)$and the sum of nitrite and nitrate concentrations 300 (i.e., $\mathrm{NO}_{2}{ }^{-} / \mathrm{NO}_{3}{ }^{-}$; Supplementary Table S3).

$301 \quad$ Environmental/physiological parameters investigated in this study explained a limited 302 amount of variation in the microbial community of mucus and tissue of the two Acropora species 303 studied (Figure 4). For example, seawater parameters explained 14\% (Chla, $\mathrm{NH}_{4}{ }^{+}$and $\mathrm{NO}_{2}{ }^{-} / \mathrm{NO}_{3}{ }^{-}$ $304)$ and $10 \%\left(\mathrm{POC}\right.$ and $\left.\mathrm{NO}_{2}{ }^{-} / \mathrm{NO}_{3}{ }^{-}\right)$of the compositional variability for the mucus microbiome in 305 A. tenuis and A. millepora, respectively (ANOVA-like permutational test for dbRDA; 306 Supplementary Table $\mathrm{S} 4) ; \mathrm{NO}_{2}{ }^{-} / \mathrm{NO}_{3}{ }^{-}$was the only explanatory environmental variable common 307 to the mucus microbiome of both Acropora species (5\% of compositional variability explained in 308 each species). In comparison, for the seawater microbiome, environmental parameters $\left(\mathrm{NO}_{2}{ }^{-}\right.$ $309 \mathrm{NO}_{3}{ }^{-}$, TSS, POC, Salinity and Chla) explained $32 \%$ of the compositional variability of the 310 microbiome (Supplementary Figure S2), suggesting greater environmental sensitivity by the 311 microbial community in the seawater compared to the coral-associated communities.

312 In contrast, tissue microbiomes of $A$. millepora and A. tenuis differed substantially in 313 their response to environmental and/or to physiological parameters. While host physiology (i.e., 314 Symbiodiniaceae density normalized to protein contents) and environment (TSS and Chla) 315 explained $6 \%$ and $10 \%$, respectively, of the variation of the tissue microbiome in $A$. tenuis, in $A$. 316 millepora, the compositional variation was solely explained (10\%) by environmental parameters $317\left(\mathrm{NO}_{2}{ }^{-} / \mathrm{NO}_{3}{ }^{-}\right.$and TSS; Variation Partitioning Analysis and ANOVA-like permutational test for 318 dbRDA; Supplementary Table S4). TSS was the only explanatory environmental variable 319 common to the tissue microbiomes of both Acropora species (total of $5 \%$ and $4 \%$ in $A$. tenuis 320 and in A. millepora, respectively).

321

\section{Correlation between bacterial families and environmental/physiological parameters}

323 The relative abundance of Synechococcaceae in tissues of both Acropora species and the mucus 324 of $A$. tenuis was negatively correlated with TSS $(\mathrm{p}=0.025-0.039$; Figure 5 and Supplementary 325 Tables S5 and S6). In contrast, Synechococcaceae was positively correlated to total $\mathrm{NO}_{2}{ }^{-} / \mathrm{NO}_{3}{ }^{-}$in 326 both species (mucus of $A$. tenuis, $\mathrm{p}=0.002$, Supplementary Table S6; and tissue of $A$. millepora, $327 \mathrm{p}=0.024$, Supplementary Table S5). For A. tenuis, Synechococcaceae abundance in the tissue 328 correlated negatively with the only significant physiological parameter (Symbiodiniaceae density 329 normalized to protein contents; $\mathrm{p}=0.025)$. In the mucus of A. millepora, the abundance of 
330 Pirellulaceae was positively correlated with $\mathrm{NO}_{2}{ }^{-} / \mathrm{NO}_{3}{ }^{-}(\mathrm{p}=0.035)$ and negatively correlated 331 with TSS $(\mathrm{p}=0.019)$, while OCS155 was positively correlated to $\mathrm{NO}_{2}{ }^{-} / \mathrm{NO}_{3}{ }^{-}(\mathrm{p}=0.015)$.

332 Proteobacteria from the mucus of A. tenuis, Pelagibacteraceae and Halomonadaceae, were both 333 strongly negative correlated with chlorophyll $a$ in the seawater (Pelagibacteraceae, $\mathrm{p}=0.013$; 334 Halomonadaceae, $\mathrm{p}=0.008)$. Additionally, Halomonadaceae correlated negatively with $\mathrm{NH}_{4}{ }^{+}(\mathrm{p}$ $335=0.005$; Figure 5 and Supplementary Tables S5 and S6).

336 Tissue-associated Endozoicimonaceae showed a strong significant positive correlation 337 with Symbiodiniaceae density normalized to protein content in A. tenuis $(\mathrm{p}=0.0003)$. In

338

339

340

341

\section{Discussion}

343

344

345

346

347

348

349

350

351

352

353

354

355

356

357

358

359

360

Microbial communities associated with corals are continually exposed to fluctuations in the surrounding environment and the physiology of their host. Previous studies have demonstrated changes in the coral microbiome in response to thermal stress (Ainsworth \& Hoegh-Guldberg, 2009; Grottoli et al., 2018; Lee et al., 2015; Thurber et al., 2009), ocean acidification (Grottoli et al., 2018; Thurber et al., 2009), organic matter enrichment (Garren \& Azam, 2012), bleaching events (Bourne et al., 2008) and other environmental and physiological factors (Glasl et al., 2019a; Guppy \& Bythell, 2006; Kelly et al., 2014; Li et al., 2015; Pollock et al., 2018). However, the coral microbiome is not homogenous across the animal and an improved understanding of the sensitivity of the microorganisms inhabiting each coral compartment is needed. This study highlights compositional differences in the bacterial communities associated with coral mucus and coral tissue, as well as with the surrounding seawater, findings that are largely consistent with previous studies (Apprill, Weber \& Santoro, 2016; Bourne \& Munn, 2005; Engelen et al., 2018; Pollock et al., 2018; Sweet, Croquer \& Bythell, 2011). Furthermore, the high similarity between mucus and seawater microbiomes (see Supplementary Tables S1 and S2, Figures 2 and 3 ) and the high dissimilarity between tissue and seawater microbiomes suggests that the mucus microbial community is more strongly influenced by the external environment than the tissue community. Similar results have been reported for other coral species in the Caribbean (Orbicella faveolata, Diploria strigosa, Montastraea cavernosa, Porites porites and Porites 
361 astreoides), where mucus and seawater shared significantly more microbial taxa than those

362 shared by tissue and seawater microbiomes (Apprill, Weber \& Santoro, 2016). Our results also

363 support that mucus microbiomes are richer and more diverse than tissue microbiomes, which is a

364 pattern corroborated by many studies (Bourne \& Munn, 2005; Koren \& Rosenberg, 2006).

365 Despite the host species-specificity of the coral microbiomes, some bacterial taxa were

366 ubiquitously associated with a particular coral compartment. For example, Flavobacteriaceae and

367 Synechococcaceae dominated the mucus of both species, while Endozoicimonaceae dominated

368 the tissue microbiome of both Acropora species. However, overall microbiome composition also

369 showed some overlap between host compartments, consistent with previous reports of overlap

370 between the mucus and tissue microbiomes of other coral species (Engelen et al., 2018; Sweet,

371 Croquer \& Bythell, 2011). This intersection is a natural feature of the coral holobiont as both

372 compartments are within the same host and because the constituents of the surface mucus layer

373 are originally produced inside the tissue (Bythell \& Wild, 2011). The sharing of some microbial

374 taxa between compartments may also arise due to methodological challenges associated with

375 retrieving samples that are exclusively mucus or coral tissue (Sweet, Croquer \& Bythell, 2011).

376 Similar methodological limitations could also obscure differences between the mucus and

377 seawater microbiomes (Brown \& Bythell, 2005).

378

379 Explanatory factors of mucus microbiome variation

380 We hypothesized that the coral mucus microbiome, which is in direct contact with seawater,

381 would be primarily correlated with seawater parameters, whereas the tissue microbiome would

382 be most affected by the physiological state of the coral host. Mucus is highly hydrated: mucocyte

383 cells release their secretions in a condensed form which then undergo a massive swelling upon

384 hydration, forming a visco-elastic gel (Brown \& Bythell, 2005). Surface mucus can therefore be

385 influenced by the presence of nutrients dissolved in the surrounding seawater (Tanaka, Ogawa \&

386 Miyajima, 2010). As expected, environmental factors (i.e. seawater parameters) were influential

387 in shaping the mucus microbiome of both species (A. millepora and A. tenuis), consistent with

388 recent studies relating changes in the mucus microbiome with environmental perturbations (Li et

389 al., 2015; Pollock et al., 2018). However, the extent of influence from environmental parameters

390 (10\% of variation) on the mucus microbiome was much lower than the influence of environment

391 on the seawater microbiome (32\% of variation), suggesting that other factors also play a role in 
392 modulating the mucus microbiome. For instance, the surrounding environment may interact with 393 host physiology and together they alter the bacterial community structure of the mucus. Mucus is 394 a nutrient-rich medium fueled by the photosynthetic activity of the Symbiodiniaceae (Brown \& 395 Bythell, 2005) and therefore it is expected that some degree of variation in its chemical 396 composition is explained by host-Symbiodiniaceae factors. For example, A. millepora and $A$. 397 tenuis at the sampling site (Geoffrey Bay at Magnetic Island) associate with distinct 398 Symbiodiniaceae (LaJeunesse et al., 2018; Ulstrup \& van Oppen, 2003; van Oppen et al., 2001). 399 A. millepora colonies were associated with Durusdinium (van Oppen et al., 2001) whereas $A$. 400 tenuis harbored Cladocopium spp. (Ulstrup \& van Oppen, 2003). Links between mucus chemical 401 composition and microbiome community structure have been proposed (Tremblay et al., 2011). 402 Physiological factors regulating the dynamics of production and release of the surface mucus 403 layer could also contribute to regulating mucus microbial composition (Glasl, Herndl \& Frade, 404 2016).

$405 \quad$ Fluctuations of $\mathrm{NH}_{4}{ }^{+}, \mathrm{NO}_{2}{ }^{-} / \mathrm{NO}_{3}{ }^{-}, \mathrm{Chl} a$ and $\mathrm{POC}$ in the surrounding seawater 406 significantly correlated with the mucus microbiome variation in Acropora species. Li et al. 407 (2015) and Chen et al. (2011) suggested that rainfall had a crucial effect on bacterial community 408 variation in the coral microbiome, being mostly associated with an increase in the relative 409 abundance of the Bacilli group (Chen et al., 2011; Li et al., 2015). In the present study, $\mathrm{NO}_{2}{ }^{-}$ $410 \mathrm{NO}_{3}{ }^{-}$(and its collinear variables daylight, particulate nitrogen and grainsize of sediments;

411 Supplementary Table S3) had the greatest influence on microbiome structure, being a significant 412 factor for both studied species. The link between rainfall and increasing nutrients (such as $\mathrm{NO}_{2}^{-}$ $413 \mathrm{NO}_{3}{ }^{-}$) is well established for inshore reefs (Fabricius, 2005). In the current study, higher 414 amounts of particulate and dissolved nutrients (but a decrease in TSS), corresponded to an 415 increase in mucus-associated Synechococcaceae, Pirellulaceae, OCS155 and Rhodobacteraceae 416 and a decrease in Halomonadaceae. For instance, Synechococcaceae in the mucus was highly 417 positively correlated with $\mathrm{NO}_{2}{ }^{-} / \mathrm{NO}_{3}{ }^{-}$and negatively correlated with TSS. These findings 418 corroborate previous work in which the abundance of free-living Synechococcus in shallow 419 coastal waters decreased significantly under lower nutrient (especially nitrate) and higher TSS 420 concentrations (Uysal \& Köksalan, 2006).

421 Dissolved nutrients, such as nitrogen and phosphorus, can affect coral physiology and 422 drive changes in the associated microbial community (Shaver et al., 2017; Thompson et al., 
423 2015). For example, organic-rich nutrients from terrestrial run-off negatively affect the health of 424 corals and promote rapid growth of opportunistic heterotrophic bacteria (e.g. Vibrionales, 425 Flavobacteriales and Rhodobacterales), thus affecting the overall composition of the coral 426 microbiome (McDevitt-Irwin et al., 2017; Weber et al., 2012). In our study, the abundance of 427 Flavobacteriaceae and Rhodobacteraceae in the mucus of $A$. tenuis correlated with TSS and $428 \mathrm{NH}_{4}{ }^{+}$, respectively. The coral holobiont, including cyanobacteria related to Synechococcus spp. 429 (Lesser et al., 2004), can also efficiently take up inorganic nitrogen, for example, as nitrogen is 430 required by the photosynthesis production of its Symbiodiniaceae symbionts (Yellowlees, Rees 431 \& Leggat, 2008). In fact, $\mathrm{NH}_{4}{ }^{+}$can be assimilated by both coral and its Symbiodiniaceae 432 (Pernice et al., 2012), and recent work has implicated bacteria such as Vibrio and Alteromonas in 433 the incorporation and translocation of $\mathrm{NH}_{4}{ }^{+}$into coral tissues and associated Symbiodiniaceae 434 (Ceh et al., 2013). Nitrifying members of the mucus microbiome, such as ammonium oxidizing 435 bacteria (e.g., Pirelullaceae) and archaea, are fueled by $\mathrm{NH}_{4}^{+}$(Beman et al., 2007; Siboni et al., 436 2008; Yang et al., 2013), and $\mathrm{NO}_{2}{ }^{-} / \mathrm{NO}_{3}{ }^{-}$can be respired by nitrate reducers putatively active in 437 coral microbiomes (Siboni et al., 2008; Yang et al., 2013). Interestingly, Pirellulaceae 438 abundances in the mucus of A. millepora positively correlated with concentrations of 439 environmental $\mathrm{NO}_{2}{ }^{-} / \mathrm{NO}_{3}{ }^{-}$, the products of ammonium oxidation. These nitrogen-cycling 440 processes mediated by microbes are highly dependent on oxygen availability, but because 441 oxygen concentration in the mucus shows strong diel fluctuations (Shashar, Cohen \& Loya, 442 1993), it is possible that both aerobic (e.g., nitrification) and anaerobic (e.g., denitrification) 443 processes happen within the mucus layer at different times of the day. Temporal dynamics in the 444 coral mucus microbiome are thus likely influenced by the individual and collective metabolic 445 capabilities of the diverse assemblage of microbes and by nutrient availability in the surrounding 446 waters.

447

448 Explanatory factors of tissue microbiome variation

449 The statistical relation between the coral tissue microbiome and the environmental and 450 physiological parameters differed between coral species. Whereas the tissue microbiome of $A$. 451 tenuis corresponded to both environment and host physiology, A. millepora correlated only with 452 environmental parameters. This difference may be associated to specific features of each species, 453 through which A. millepora could modulate the internal environment and create more stable 
454 intra-tissue conditions than $A$. tenuis (e.g., via skeletal light modulation, host morphology and 455 tissue thickness, sensu Enriquez, Mendez \& Iglesias-Prieto, 2005). A non-mutually exclusive 456 alternative explanation is the influence of the algal symbiont (Symbiodiniaceae) genotype 457 associated to the host. Little et al. (2004) investigated Symbiodiniaceae communities associated 458 with A. millepora and A. tenuis on Magnetic Island demonstrating that the coral-algal 459 endosymbiotic relationship in Acropora spp. is distinct between species, dynamic and flexible 460 (corals associate with different Symbiodiniaceae types at different life stages, for example), and 461 contributes significantly to physiological attributes of the coral holobiont. For example, different 462 algal genotypes can affect the nutrient availability (e.g. carbon and nitrogen) in the coral 463 holobiont (Pernice et al., 2015; Bayliss et al., 2019). Environmental factors such as seawater 464 temperature can also lead to temporal changes in the symbiont community (Cooper et al., 2011; 465 Howells et al., 2012; Rocker, Willis \& Bay, 2012). As the microbiome is strongly associated to 466 the coral holobiont, any disturbance in the host-Symbiodiniaceae relationship may have indirect 467 effects on the microbial composition and its response to environmental and physiological factors. 468 Other studies demonstrate the influence of Symbiodiniaceae on the host microbial community 469 and also support the idea that these two components of the coral holobiont are finely tuned (Glasl

470 471 472 473 474 475 476 477 478 479 480 481 482 483 484 et al., 2017; Grottoli et al., 2018; Littman, Bourne \& Willis, 2010; Littman, Willis \& Bourne, 2009b; Quigley et al., 2019). In the present study, Endozoicimonaceae were strongly positively correlated with the Symbiodiniaceae density in the tissue of A. tenuis and negatively correlated with $\mathrm{NO}_{2}^{-} / \mathrm{NO}_{3}{ }^{-}$in $A$. millepora (see Figure 5). These results are to some extent at odds with experimental results showing a stable dominance of Endozoicimonaceae in tissues of Pocillopora verrucosa irrespective of excess dissolved organic nitrogen and despite a bleaching phenomenon concomitant with structural changes in its Symbiodiniaceae community (Pogoreutz et al., 2018).

Besides the diversity of Symbiodiniaceae associated to each coral species, other factors can affect the coral and its response to environmental parameters, such as photochemical efficiency (Fv/Fm) and symbiont density (Cunning \& Baker, 2014; Da-Anoy, Cabaitan \& Conaco, 2019). For instance, Da-Anoy, Cabaitan \& Conaco (2019) demonstrated a greater reduction of $\mathrm{Fv} / \mathrm{Fm}$ in $A$. tenuis in response to elevated temperatures compared to $A$. millepora and the temperature responses of the corals did not directly correlate with their associated seemingly associated Symbiodiniaceae. This suggests that other species-specific physiological 
485 factors could modulate the responses of the coral to the environment and, indirectly, influence 486 the tissue-associated microbiome. One such factor is the way coral-associated microbial 487 aggregates (CAMAs) are distributed throughout the tissue, which varies within populations and 488 can vary among coral species (Work \& Aeby, 2014; Wada et al., 2019).

489

490

491

492

493

494

495

496

497

498

499

500

501

502

503

504

505

506

507

508

509

510

511

\section{Acknowledgements}

513 We thank Michele Skuza, Neale Johnston and the AIMS water quality team for their help with 514 analyzing the water quality samples. We thank Heidi Luter, Katarina Damjanovic and Joe 
515 Gioffre for their assistance in the field. We also thank Sara Bell, Florita Flores and Carlos

516 Alvarez for their expertise in the laboratory.

517

518

519

520

521

522

523

524

525

526

527

528

529

530

531

532

533

534

535

536

537

538

539

540

541

542

543

544

\section{References}

Agostini, S., Suzuki, Y., Higuchi, T., Casareto, B. E., Yoshinaga, K., Nakano, Y., \& Fujimura, H. (2012). Biological and chemical characteristics of the coral gastric cavity. Coral Reefs, 31(1), 147-156. https://doi.org/10.1007/s00338-011-0831-6

Ainsworth, T. D., \& Hoegh-Guldberg, O. (2009). Bacterial communities closely associated with coral tissues vary under experimental and natural reef conditions and thermal stress. Aquatic Biology, 4, 289-296. https://doi.org/10.3354/ab00102

Ainsworth, T. D., Krause, L., Bridge, T., Torda, G., Raina, J.-B., Zakrzewski, M., Gates, R. D., Padilla-Gamiño, J. L., Spalding, H. L., Smith, C., Woolsey, E. S., Bourne, D. G., Bongaerts, P., Hoegh-Guldberg, O., \& Leggat, W. (2015). The coral core microbiome identifies rare bacterial taxa as ubiquitous endosymbionts. The ISME Journal, 9(10), 2261-2274. https://doi.org/10.1038/ismej.2015.39

Apprill, A., Weber, L. G., \& Santoro, A. E. (2016). Distinguishing between Microbial Habitats Unravels Ecological Complexity in Coral Microbiomes. MSystems, 1(5), e00143-16, /msys/1/5/e00143-16.atom. https://doi.org/10.1128/mSystems.00143-16

Bayer, T., Neave, M. J., Alsheikh-Hussain, A., Aranda, M., Yum, L. K., Mincer, T., Hughen, K., Apprill, A., \& Voolstra, C. R. (2013). The Microbiome of the Red Sea Coral Stylophora pistillata Is Dominated by Tissue-Associated Endozoicomonas Bacteria. Applied and Environmental Microbiology, 79(15), 4759-4762. https://doi.org/10.1128/AEM.00695$\underline{13}$ 
545 Bayliss, S.L.J., Scott, Z.R., Coffroth, M.A., \& terHorst, C.P. (2019) Genetic variation in

546

547

548

549

550

551

552

553

554

555

556

557

558

559

560

561

562

563

564

565

566

567

568

569

570

571

572

573

574

575

Breviolum antillogorgium, a coral reef symbiont, in response to temperature and nutrients. Ecology and Evolution, 9, 2803-2813. https://doi.org/10.1002/ece3.4959

Beman, J. M., Roberts, K. J., Wegley, L., Rohwer, F., \& Francis, C. A. (2007). Distribution and Diversity of Archaeal Ammonia Monooxygenase Genes Associated with Corals. Applied and Environmental Microbiology, 73(17), 5642-5647. https://doi.org/10.1128/AEM.00461-07

Benjamini, Y., \& Hochberg, Y. (1995). Controlling the false discovery rate: a practical and powerful approach to multiple testing. Journal of the Royal statistical society: series B (Methodological), 57(1), 289-300.

Blanchet, F. G., Legendre, P., \& Borcard, D. (2008). Forward selection of explanatory variables. Ecology, 89(9), 2623-2632. https://doi.org/10.1890/07-0986.1

Bourne, D. G., Dennis, P. G., Uthicke, S., Soo, R. M., Tyson, G. W., \& Webster, N. (2013). Coral reef invertebrate microbiomes correlate with the presence of photosymbionts. The ISME Journal, 7(7), 1452-1458. https://doi.org/10.1038/ismej.2012.172

Bourne, D. G., Morrow, K. M., \& Webster, N. S. (2016). Insights into the Coral Microbiome: Underpinning the Health and Resilience of Reef Ecosystems. Annual Review of Microbiology, 70(1), 317-340. https://doi.org/10.1146/annurev-micro-102215-095440

Bourne, D. G., \& Munn, C. B. (2005). Diversity of bacteria associated with the coral Pocillopora damicornis from the Great Barrier Reef. Environmental Microbiology, 7(8), 1162-1174. https://doi.org/10.1111/j.1462-2920.2005.00793.x

Bourne, D., Iida, Y., Uthicke, S., \& Smith-Keune, C. (2008). Changes in coral-associated microbial communities during a bleaching event. The ISME Journal, 2(4), 350-363. https://doi.org/10.1038/ismej.2007.112

PeerJ reviewing PDF | (2020:02:45510:2:0:NEW 6 Jul 2020) 
576

577 Brown, B., \& Bythell, J. (2005). Perspectives on mucus secretion in reef corals. Marine Ecology

578 Progress Series, 296, 291-309. https://doi.org/10.3354/meps296291

579

580

581

582

583

584

585

586

587

588

589

590

591

592

593

594

595

596

597

598

599

600

601

602

603

604

605

606

Brown, M. V., van de Kamp, J., Ostrowski, M., Seymour, J. R., Ingleton, T., Messer, L. F., Jeffries, T., Siboni, N., Laverock, B., Bibiloni-Isaksson, J., Nelson, T. M., Coman, F., Davies, C. H., Frampton, D., Rayner, M., Goossen, K., Robert, S., Holmes, B., Abell, G. C. J., ... Bodrossy, L. (2018). Systematic, continental scale temporal monitoring of marine pelagic microbiota by the Australian Marine Microbial Biodiversity Initiative. Scientific Data, 5(1), 180130. https://doi.org/10.1038/sdata.2018.130

Bythell, J. C., \& Wild, C. (2011). Biology and ecology of coral mucus release. Journal of Experimental Marine Biology and Ecology, 408(1-2), 88-93. https://doi.org/10.1016/j.jembe.2011.07.028

Ceh, J., Kilburn, M. R., Cliff, J. B., Raina, J.-B., van Keulen, M., \& Bourne, D. G. (2013). Nutrient cycling in early coral life stages: Pocillopora damicornis larvae provide their algal symbiont ( Symbiodinium ) with nitrogen acquired from bacterial associates. Ecology and Evolution, 3(8), 2393-2400. https://doi.org/10.1002/ece3.642

Ceh, J., van Keulen, M., \& Bourne, D. G. (2011). Coral-associated bacterial communities on Ningaloo Reef, Western Australia: Coral bacterial communities, Ningaloo Reef. FEMS Microbiology Ecology, 75(1), 134-144. $\quad$ https://doi.org/10.1111/j.1574$\underline{6941.2010 .00986 . x}$

Chen, C.-P., Tseng, C.-H., Chen, C. A., \& Tang, S.-L. (2011). The dynamics of microbial partnerships in the coral Isopora palifera. The ISME Journal, 5, 728-740.

Chen, H., \& Boutros, P. C. (2011). VennDiagram: A package for the generation of highlycustomizable Venn and Euler diagrams in R. 12(1), 35. 
607 Commonwealth of Australia. (2019). http://www.bom.gov.au/?ref=logo

608

609 Cooper, T. F., Berkelmans, R., Ulstrup, K. E., Weeks, S., Radford, B., Jones, A. M., Doyle, J., 610 Canto, M., O'Leary, R. A., \& van Oppen, M. J. H. (2011). Environmental Factors

611

612

613

614

615

616

617

618

619

620

621

622

623

624

625

626

627

628

629

630

631

632

633

634

635

636

637

Controlling the Distribution of Symbiodinium Harboured by the Coral Acropora millepora on the Great Barrier Reef. PLoS ONE, 6(10), e25536. https://doi.org/10.1371/journal.pone.0025536

Cunning, R., \& Baker, A. C. (2014). Not just who, but how many: the importance of partner abundance in reef coral symbioses. Frontiers in microbiology, 5, 400.

Da-Anoy, J. P., Cabaitan, P. C., \& Conaco, C. (2019). Species variability in the response to elevated temperature of select corals in north-western Philippines. Journal of the Marine Biological Association of the United Kingdom, 99(6), 1273-1279.

Dana, J. D. (1846). United States Exploring Expedition during the years 1838-1842. 7, 1-740.

Devlin M.J. \& Lourey M.J. (2000) Water quality - field and analytical procedures. In: LtMotGB R, editor. Standard Operational Procedure, vol. 6. Townsville: Australian Institute of Marine Science.

Dormann, C. F., Elith, J., Bacher, S., Buchmann, C., Carl, G., Carré, G., Marquéz, J. R. G., Gruber, B., Lafourcade, B., Leitão, P. J., Münkemüller, T., McClean, C., Osborne, P. E., Reineking, B., Schröder, B., Skidmore, A. K., Zurell, D., \& Lautenbach, S. (2013). Collinearity: A review of methods to deal with it and a simulation study evaluating their performance. Ecography, 36(1), 27-46. $\quad$ https://doi.org/10.1111/j.1600$\underline{0587.2012 .07348 . x}$

Edgar, R. C. (2010). Search and clustering orders of magnitude faster than BLAST. Bioinformatics, 26(19), 2460-2461. https://doi.org/10.1093/bioinformatics/btq461 
638 Ehrenberg, C. (1834). Contributions to the physiological knowledge of the coral animals in

639

640

641

642

643

644

645

646

647

648

649

650

651

652

653

654

655

656

657

658

659

660

661

662

663

664

665

666

667

general, and especially of the Red Sea, together with an experiment on the physiological systematics of the same. 1, 225-380.

Engelen, A. H., Aires, T., Vermeij, M. J. A., Herndl, G. J., Serrão, E. A., \& Frade, P. R. (2018). Host Differentiation and Compartmentalization of Microbial Communities in the Azooxanthellate Cupcorals Tubastrea coccinea and Rhizopsammia goesi in the Caribbean. Frontiers in Marine Science, 5, 391. https://doi.org/10.3389/fmars.2018.00391

Enriquez, S., Mendez, E. R., \& Iglesias-Prieto, R. I. (2005). Multiple scattering on coral skeletons enhances light absorption by symbiotic algae. Limnology and Oceanography, 50(4), 1025-1032. https://doi.org/10.4319/10.2005.50.4.1025

Fabricius, K. E. (2005). Effects of terrestrial runoff on the ecology of corals and coral reefs: Review and synthesis. Marine Pollution Bulletin, 50(2), 125-146. https://doi.org/10.1016/j.marpolbul.2004.11.028

Frade, P. R., Bongaerts, P., Winkelhagen, A. J. S., Tonk, L., Bak, R. P. M. (2008). In situ photobiology of corals over large depth ranges: A multivariate analysis on the roles of environment, host, and algal symbiont. Limnology and Oceanography, 53(6), 2711-2723. https://doi.org/10.4319/LO.2008.53.6.2711

Frade, P. R., Roll, K., Bergauer, K., \& Herndl, G. J. (2016a). Archaeal and bacterial communities associated with the surface mucus of Caribbean corals differ in their degree of host specificity and community turnover over reefs. PLOS ONE, 11(1), e0144702. https://doi.org/10.1371/journal.pone.0144702

Frade, P. R., Schwaninger, V., Glasl, B., Sintes, E., Hill, R. W., Simó, R., \& Herndl, G. J. (2016b). Dimethylsulfoniopropionate in corals and its interrelations with bacterial 
668

669

670

671

672

673

674

675

676

677

678

679

680

681

682

683

684

685

686

687

688

689

690

691

692

693

694

695

696

697

698

assemblages in coral surface mucus. Environmental Chemistry, 13(2), 252. https://doi.org/10.1071/EN15023

Frias-Lopez, J., L. Zerkle, A., T. Bonheyo, G., \& W. Fouke, B. (2002). Partitioning of bacterial communities between seawater and healthy, black band diseased, and dead coral surfaces. Applied and Environmental Microbiology, 68(5), 2214-2228. https://doi.org/10.1128/AEM.68.5.2214-2228.2002

Garren, M., \& Azam, F. (2012). Corals shed bacteria as a potential mechanism of resilience to organic matter enrichment. The ISME Journal, 6(6), 1159-1165. https://doi.org/10.1038/ismej.2011.180

Glasl, B., Bongaerts, P., Elisabeth, N. H., Hoegh-Guldberg, O., Herndl, G. J., \& Frade, P. R. (2017). Microbiome variation in corals with distinct depth distribution ranges across a shallow-mesophotic gradient (15-85 m). Coral Reefs, 36(2), 447-452. https://doi.org/10.1007/s00338-016-1517-x

Glasl, B., Bourne, D. G., Frade, P. R., Thomas, T., Schaffelke, B., \& Webster, N. S. (2019a). Microbial indicators of environmental perturbations in coral reef ecosystems. Microbiome, 7(1), 94. https://doi.org/10.1186/s40168-019-0705-7

Glasl, B., Herndl, G. J., \& Frade, P. R. (2016). The microbiome of coral surface mucus has a key role in mediating holobiont health and survival upon disturbance. The ISME Journal, 10(9), 2280-2292. https://doi.org/10.1038/ismej.2016.9

Glasl, B., Smith, C. E., Bourne, D. G., \& Webster, N. S. (2019b). Disentangling the effect of host-genotype and environment on the microbiome of the coral Acropora tenuis. PeerJ, 7, e6377. https://doi.org/10.7717/peerj.6377

Grottoli, A. G., Dalcin Martins, P., Wilkins, M. J., Johnston, M. D., Warner, M. E., Cai, W.-J., Melman, T. F., Hoadley, K. D., Pettay, D. T., Levas, S., \& Schoepf, V. (2018). Coral 
699

700

701

702

703

704

705

706

707

708

709

710

711

712

713

714

715

716

717

718

719

720

721

722

723

724

725

726

727

728

physiology and microbiome dynamics under combined warming and ocean acidification. PLOS ONE, 13(1), e0191156. https://doi.org/10.1371/journal.pone.0191156

Guppy, R., \& Bythell, J. (2006). Environmental effects on bacterial diversity in the surface mucus layer of the reef coral Montastraea faveolata. Marine Ecology Progress Series, 328, 133-142. https://doi.org/10.3354/meps328133

Hong, M.-J., Yu, Y.-T., Chen, C. A., Chiang, P.-W., \& Tang, S.-L. (2009). Influence of species specificity and other factors on bacteria associated with the coral Stylophora pistillata in Taiwan. Applied and Environmental Microbiology, 75(24), 7797-7806. https://doi.org/10.1128/AEM.01418-09

Howells, E. J., Beltran, V. H., Larsen, N. W., Bay, L. K., Willis, B. L., \& van Oppen, M. J. H. (2012). Coral thermal tolerance shaped by local adaptation of photosymbionts. Nature Climate Change, 2(2), 116-120. https://doi.org/10.1038/nclimate1330

Iglesias-Prieto, R. \& Trench R. K. (1997) Acclimation and adaptation to irradiance in symbiotic dinoflagellates. II. Response of chlorophyll-protein complexes to different photon-flux densities. Marine Biology, 130(1), 23-33.

Johnson, J. B., \& Omland, K. S. (2004). Model selection in ecology and evolution. Trends in Ecology \& Evolution, 19(2), 101-108. https://doi.org/10.1016/j.tree.2003.10.013

Kelly, L. W., Williams, G. J., Barott, K. L., Carlson, C. A., Dinsdale, E. A., Edwards, R. A., Haas, A. F., Haynes, M., Lim, Y. W., McDole, T., Nelson, C. E., Sala, E., Sandin, S. A., Smith, J. E., Vermeij, M. J. A., Youle, M., \& Rohwer, F. (2014). Local genomic adaptation of coral reef-associated microbiomes to gradients of natural variability and anthropogenic stressors. Proceedings of the National Academy of Sciences, 111(28), 10227-10232. https://doi.org/10.1073/pnas.1403319111 
729 Klaus, J. S., Janse, I., Heikoop, J. M., Sanford, R. A., \& Fouke, B. W. (2007). Coral microbial

730

731

732

733

734

735

736

737

738

739

740

741

742

743

744

745

746

747

748

749

750

751

752

753

754

755

756

757

758

759 communities, zooxanthellae and mucus along gradients of seawater depth and coastal pollution. Environmental Microbiology, 9(5), 1291-1305. https://doi.org/10.1111/j.1462$\underline{2920.2007 .01249 . x}$

Koren, O., \& Rosenberg, E. (2006). Bacteria Associated with Mucus and Tissues of the Coral Oculina patagonica in Summer and Winter. Applied and Environmental Microbiology, 72(8), 5254-5259. https://doi.org/10.1128/AEM.00554-06

LaJeunesse, T. C., Parkinson, J. E., Gabrielson, P. W., Jeong, H. J., Reimer, J. D., Voolstra, C. R., \& Santos, S. R. (2018). Systematic revision of Symbiodiniaceae highlights the antiquity and diversity of coral endosymbionts. Current Biology, 28(16), 2570-2580.

Lane, D. J. (1991). 16S/23S rRNA sequencing. 115-175.

Larsson, J. (2020). eulerr: Area-proportional euler and venn diagrams with ellipses. R package version 6.1.0, https://cran.r-project.org/package=eulerr.

Lee, S. T. M., Davy, S. K., Tang, S.-L., Fan, T.-Y., \& Kench, P. S. (2015). Successive shifts in the microbial community of the surface mucus layer and tissues of the coral Acropora muricata under thermal stress. FEMS Microbiology Ecology, 91(12), fiv142. https://doi.org/10.1093/femsec/fiv142

Legendre, P., \& Anderson, M. J. (1999). Distance-based redundancy analysis: testing multispecies responses in multifactorial ecological experiments. Ecological Monographs, 69(1), 1-24. https://doi.org/10.1890/0012-9615(1999)069[0001:DBRATM]2.0.CO;2

Lema, K. A., Willis, B. L., \& Bourne, D. G. (2012). Corals form characteristic associations with symbiotic nitrogen-fixing bacteria. Applied and Environmental Microbiology, 78(9), 3136-3144. https://doi.org/10.1128/AEM.07800-11

PeerJ reviewing PDF | (2020:02:45510:2:0:NEW 6 Jul 2020) 
760 Lesser M.P., Mazel C.H., Gorbunov M.Y., Falkowski P.G. (2004). Discovery of symbiotic

761

762

763

764

765

766

767

768

769

770

771

772

773

774

775

776

777

778

779

780

781

782

783

784

785

786

787

788

789

790 nitrogen-fixing cyanobacteria in corals. Science, 305, 997-1000

Li, J., Chen, Q., Long, L.-J., Dong, J.-D., Yang, J., \& Zhang, S. (2015). Bacterial dynamics within the mucus, tissue and skeleton of the coral Porites lutea during different seasons. Scientific Reports, 4(1), 7320. https://doi.org/10.1038/srep07320

Little, A. F. (2004). Flexibility in algal endosymbioses shapes growth in reef corals. Science, 304(5676), 1492-1494. https://doi.org/10.1126/science.1095733

Littman, R. A., Bourne, D. G., \& Willis, B. L. (2010). Responses of coral-associated bacterial communities to heat stress differ with Symbiodinium type on the same coral host. Molecular Ecology, 19(9), 1978-1990. $\quad$ https://doi.org/10.1111/j.1365294X.2010.04620.X

Littman, R. A., Willis, B. L., Pfeffer, C., \& Bourne, D. G. (2009a). Diversities of coralassociated bacteria differ with location, but not species, for three acroporid corals on the Great Barrier Reef: Diversity of coral-associated bacteria. FEMS Microbiology Ecology, 68(2), 152-163. https://doi.org/10.1111/j.1574-6941.2009.00666.x

Littman, R., Willis, B., \& Bourne, D. G. (2009b). Bacterial communities of juvenile corals infected with different Symbiodinium (dinoflagellate) clades. Marine Ecology Progress Series, 389, 45-59. https://doi.org/10.3354/meps08180

Magoc, T., \& Salzberg, S. L. (2011). FLASH: Fast length adjustment of short reads to improve https://doi.org/10.1093/bioinformatics/btr507

McDevitt-Irwin, J. M., Baum, J. K., Garren, M., \& Vega Thurber, R. L. (2017). Responses of coral-associated bacterial communities to local and global stressors. Frontiers in Marine Science, 4, 262. https://doi.org/10.3389/fmars.2017.00262 
791

792

793

794

795

796

797

798

799

800

801

802

803

804

805

806

807

808

809

810

811

812

813

814

815

816

817

818

819

820

821

McMurdie, P. J., \& Holmes, S. (2013). phyloseq: An R package for reproducible interactive analysis and graphics of microbiome census data. PLoS ONE, 8(4), e61217. https://doi.org/10.1371/journal.pone.0061217

Morris, J. J., Johnson, Z. I., Szul, M. J., Keller, M., \& Zinser, E. R. (2011). Dependence of the cyanobacterium Prochlorococcus on hydrogen peroxide scavenging microbes for growth at the ocean's surface. PLoS ONE, 6(2), e16805. https://doi.org/10.1371/journal.pone.0016805

Muller-Parker, G., D’Elia, C. F., \& Cook, C. B. (2015). Interactions between corals and their symbiotic algae. In C. Birkeland (Ed.), Coral Reefs in the Anthropocene (pp. 99-116). Springer Netherlands. https://doi.org/10.1007/978-94-017-7249-5_5

Neave, M. J., Apprill, A., Ferrier-Pagès, C., \& Voolstra, C. R. (2016). Diversity and function of prevalent symbiotic marine bacteria in the genus Endozoicomonas. Applied Microbiology and Biotechnology, 100(19), 8315-8324. https://doi.org/10.1007/s00253-016-7777-0

Neave, M. J., Rachmawati, R., Xun, L., Michell, C. T., Bourne, D. G., Apprill, A., \& Voolstra, C. R. (2017). Differential specificity between closely related corals and abundant Endozoicomonas endosymbionts across global scales. The ISME Journal, 11(1), 186200. https://doi.org/10.1038/ismej.2016.95

Oksanen J., Blanchet F.G., Kindt R., Legendre P., Minchin P.R., O’Hara R.B., Simpson G.L., Solymos P., Stevens M.H.H., Wagner H. (2013). vegan: community ecology package. R packageversion 2.0-9. Available at http://CRAN.R-project.org/package=vegan.

Pernice, M., Meibom, A., van den Heuvel, A., Kopp, C., Domart-Coulon, I., Hoegh-Guldberg, O., \& Dove, S. (2012). A single-cell view of ammonium assimilation in coraldinoflagellate symbiosis. The ISME Journal, 6(7), 1314-1324. https://doi.org/10.1038/ismej.2011.196 
822

823 Pernice, M., Dunn, S.R., Tonk, L., Dove, S., Domart-Coulon, I., Hoppe, P., Schintlmeister, A.,

824

825

826 Wagner, M., \& Meibom, A. (2015) A nanoscale secondary ion mass spectrometry study

827

828

829

830

831 of dinoflagellate functional diversity in reef-building corals. Environmental Microbiology 17(10), 3570-3580. doi:10.1111/1462-2920.12518

832

833

Pollock, F. J., Lamb, J. B., Field, S. N., Heron, S. F., Schaffelke, B., Shedrawi, G., Bourne, D.

834

835

836

G., \& Willis, B. L. (2014). Sediment and turbidity associated with offshore dredging

Pogoreutz C, Radecker N, Cardenas A, Gardes A, Wild C, and Voolstra CR. 2018. Dominance of Endozoicomonas bacteria throughout coral bleaching and mortality suggests structural inflexibility of the Pocillopora verrucosa microbiome. Ecology and Evolution 8:22402252. 10.1002/ece 3.3830

837

838

Pollock, F. J., McMinds, R., Smith, S., Bourne, D. G., Willis, B. L., Medina, M., Thurber, R. V.,

839 increase coral disease prevalence on nearby reefs. PLoS ONE, 9(7), e102498. https://doi.org/10.1371/journal.pone.0102498

840

841 \& Zaneveld, J. R. (2018). Coral-associated bacteria demonstrate phylosymbiosis and

842

843 Quigley, K. M., Alvarez-Roa, C., Torda, G., Bourne, D. G., \& Willis, B. L. (2019). Co-dynamics 844 of Symbiodiniaceae and bacterial populations during the first year of symbiosis with 846 cophylogeny. Nature Communications, 9(1), 4921. https://doi.org/10.1038/s41467-018-

849

850 Acropora tenuis juveniles. MicrobiologyOpen. https://doi.org/10.1002/mbo3.959 $\underline{07275-\mathrm{x}}$

852

Rädecker, N., Pogoreutz, C., Voolstra, C. R., Wiedenmann, J., \& Wild, C. (2015). Nitrogen cycling in corals: The key to understanding holobiont functioning? Trends in Microbiology, 23(8), 490-497. https://doi.org/10.1016/j.tim.2015.03.008 
853

854 Rocker, M. M., Willis, B. L., \& Bay, L. K. (2012). Thermal stress-related gene expression in 855 corals with different Symbiodinium types. In Proc 12th Int Coral Reef Symp 9, 1-5).

856

857

858

859

860

861

862

863

864

865

866

867

868

869

870

871

872

873

874

875

876

877

878

879

880

881

882

Rosado, P. M., Leite, D. C. A., Duarte, G. A. S., Chaloub, R. M., Jospin, G., Nunes da Rocha, U., P. Saraiva, J., Dini-Andreote, F., Eisen, J. A., Bourne, D. G., \& Peixoto, R. S. (2019). Marine probiotics: Increasing coral resistance to bleaching through microbiome manipulation. The ISME Journal, 13(4), 921-936. https://doi.org/10.1038/s41396-018$\underline{0323-6}$

Rohwer, F., Seguritan, V., Azam, F., \& Knowlton, N. (2002). Diversity and distribution of coralassociated bacteria. Marine Ecology Progress Series, 243, 1-10.

Schloss, P. D., Westcott, S. L., Ryabin, T., Hall, J. R., Hartmann, M., Hollister, E. B., Lesniewski, R. A., Oakley, B. B., Parks, D. H., Robinson, C. J., Sahl, J. W., Stres, B., Thallinger, G. G., van Horn, D. J., \& Weber, C. F. (2009). Introducing mothur: OpenSource, Platform-Independent, Community-Supported Software for Describing and Comparing Microbial Communities. Applied and Environmental Microbiology, 75(23), 7537-7541. https://doi.org/10.1128/AEM.01541-09

Shashar, N., Cohen, Y., \& Loya, Y. (1993). Extreme diel fluctuations of oxygen in diffusive boundary layers surrounding stony corals. The Biological Bulletin, 185(3), 455-461. https://doi.org/10.2307/1542485

Shaver, E. C., Shantz, A. A., McMinds, R., Burkepile, D. E., Vega Thurber, R. L., \& Silliman, B. R. (2017). Effects of predation and nutrient enrichment on the success and microbiome of a foundational coral. Ecology, 98(3), 830-839. https://doi.org/10.1002/ecy.1709

Siboni, N., Ben-Dov, E., Sivan, A., \& Kushmaro, A. (2008). Global distribution and diversity of coral-associated Archaea and their possible role in the coral holobiont nitrogen cycle. 
883

884

885

886

887

888

889

890

891

892

893

894

895

896

897

898

899

900

901

902

903

904

905

906

907

908

909

910

911

912

913

Environmental Microbiology, 10(11), 2979-2990. https://doi.org/10.1111/j.1462$\underline{2920.2008 .01718 . \mathrm{x}}$

Ssekagiri, A., Sloan, W. T., \& Ijaz, U. Z. (2017). microbiomeSeq: An R package for analysis of microbial communities in an environmental context. https://doi.org/10.13140/rg.2.2.17108.71047

Sweet, M. J., Croquer, A., \& Bythell, J. C. (2011). Bacterial assemblages differ between compartments within the coral holobiont. Coral Reefs, 30(1), 39-52. https://doi.org/10.1007/s00338-010-0695-1

Tanaka, Y., Ogawa, H., \& Miyajima, T. (2010). Effects of nutrient enrichment on the release of dissolved organic carbon and nitrogen by the scleractinian coral Montipora digitata. Coral Reefs, 29(3), 675-682. https://doi.org/10.1007/s00338-010-0639-9

Thompson, J. R., Rivera, H. E., Closek, C. J., \& Medina, M. (2015). Microbes in the coral holobiont: Partners through evolution, development, and ecological interactions. Frontiers in Cellular and Infection Microbiology, 4. https://doi.org/10.3389/fcimb.2014.00176

Thurber, R. V., Willner-Hall, D., Rodriguez-Mueller, B., Desnues, C., Edwards, R. A., Angly, F., Dinsdale, E., Kelly, L., \& Rohwer, F. (2009). Metagenomic analysis of stressed coral holobionts. Environmental Microbiology, 11(8), 2148-2163. https://doi.org/10.1111/j.1462-2920.2009.01935.x

Tremblay, P., Weinbauer, M. G., Rottier, C., Guérardel, Y., Nozais, C., \& Ferrier-Pagès, C. (2011). Mucus composition and bacterial communities associated with the tissue and skeleton of three scleractinian corals maintained under culture conditions. Journal of the Marine Biological Association of the United Kingdom, 91(3), 649-657. https://doi.org/10.1017/S002531541000130X 
914 Turner, S., Pryer, K. M., Miao, V. P., \& Palmer, J. D. (1999). Investigating deep phylogenetic

915

916

917

918

919

920

921

922

923

924

925

926

927

928

929

930

931

932

933

934

935

936

937

938

939

940

941

942

943

944

relationships among cyanobacteria and plastids by small subunit rRNA sequence analysis 1. Journal of Eukaryotic Microbiology, 46(4), 327-338.

Ulstrup, K. E., \& Van Oppen, M. J. H. (2003). Geographic and habitat partitioning of genetically distinct zooxanthellae (Symbiodinium) in Acropora corals on the Great Barrier Reef. Molecular Ecology, 12(12), 3477-3484.

Uysal, Z., \& Köksalan, İ. (2006). The annual cycle of Synechococcus (cyanobacteria) in the northern Levantine Basin shelf waters (Eastern Mediterranean). Marine Ecology, 27(3), 187-197.

van Oppen, M. J., Palstra, F. P., Piquet, A. M. T., \& Miller, D. J. (2001). Patterns of coraldinoflagellate associations in Acropora: significance of local availability and physiology of Symbiodinium strains and host-symbiont selectivity. Proceedings of the Royal Society of London. Series B: Biological Sciences, 268(1478), 1759-1767.

Wada, N., Ishimochi, M., Matsui, T., Pollock, F. J., Tang, S. L., Ainsworth, T. D., Willis, B. L., Mano, N., \& Bourne, D. G. (2019). Characterization of coral-associated microbial aggregates (CAMAs) within tissues of the coral Acropora hyacinthus. Scientific Reports, 9(1), 14662. doi:10.1038/s41598-019-49651-7

Wang, Q., Garrity, G. M., Tiedje, J. M., \& Cole, J. R. (2007). Naive Bayesian classifier for rapid assignment of rRNA sequences into the new bacterial taxonomy. Applied and Environmental Microbiology, 73(16), 5261-5267. https://doi.org/10.1128/AEM.00062$\underline{07}$

Weber, M., de Beer, D., Lott, C., Polerecky, L., Kohls, K., Abed, R. M. M., Ferdelman, T. G., \& Fabricius, K. E. (2012). Mechanisms of damage to corals exposed to sedimentation. Proceedings of the National Academy of Sciences, 109(24), E1558-E1567. https://doi.org/10.1073/pnas.1100715109

Peer) reviewing PDF | (2020:02:45510:2:0:NEW 6 Jul 2020) 
945

946 Work, T., \& Aeby, G. (2014). Microbial aggregates within tissues infect a diversity of corals 947 throughout the Indo-Pacific. Marine Ecology Progress Series 500, 1-9.

948

949 Yang, S., Sun, W., Zhang, F., \& Li, Z. (2013). Phylogenetically diverse denitrifying and 950 ammonia-oxidizing bacteria in corals Alcyonium gracillimum and Tubastraea coccinea.

951 Marine Biotechnology, 15(5), 540-551. https://doi.org/10.1007/s10126-013-9503-6

952

953 Yellowlees, D., Rees, T. A. V., \& Leggat, W. (2008). Metabolic interactions between algal 954 symbionts and invertebrate hosts. Plant, Cell \& Environment, 31(5), 679-694. $955 \quad$ https://doi.org/10.1111/j.1365-3040.2008.01802.x

956

957 Yilmaz, P., Parfrey, L. W., Yarza, P., Gerken, J., Pruesse, E., Quast, C., Schweer, T., Peplies, J., 958 Ludwig, W., \& Glöckner, F. O. (2014). The SILVA and "All-species Living Tree Project 959 (LTP)" taxonomic frameworks. Nucleic Acids Research, 42(D1), D643-D648. 960 https://doi.org/10.1093/nar/gkt1209

961 


\section{Figure 1}

Compartment-specific microbiome composition of Acropora tenuis and Acropora millepora.

Microbial community composition (size indicates mean relative abundance and color represents standard error) resolved for the surface mucus layer and tissue of two Acropora coral species (A. tenuis and A. millepora), and surrounding seawater, based on partial $16 \mathrm{~S}$ rRNA gene amplicon sequencing. Only the 25 most abundant families across all samples are represented. 


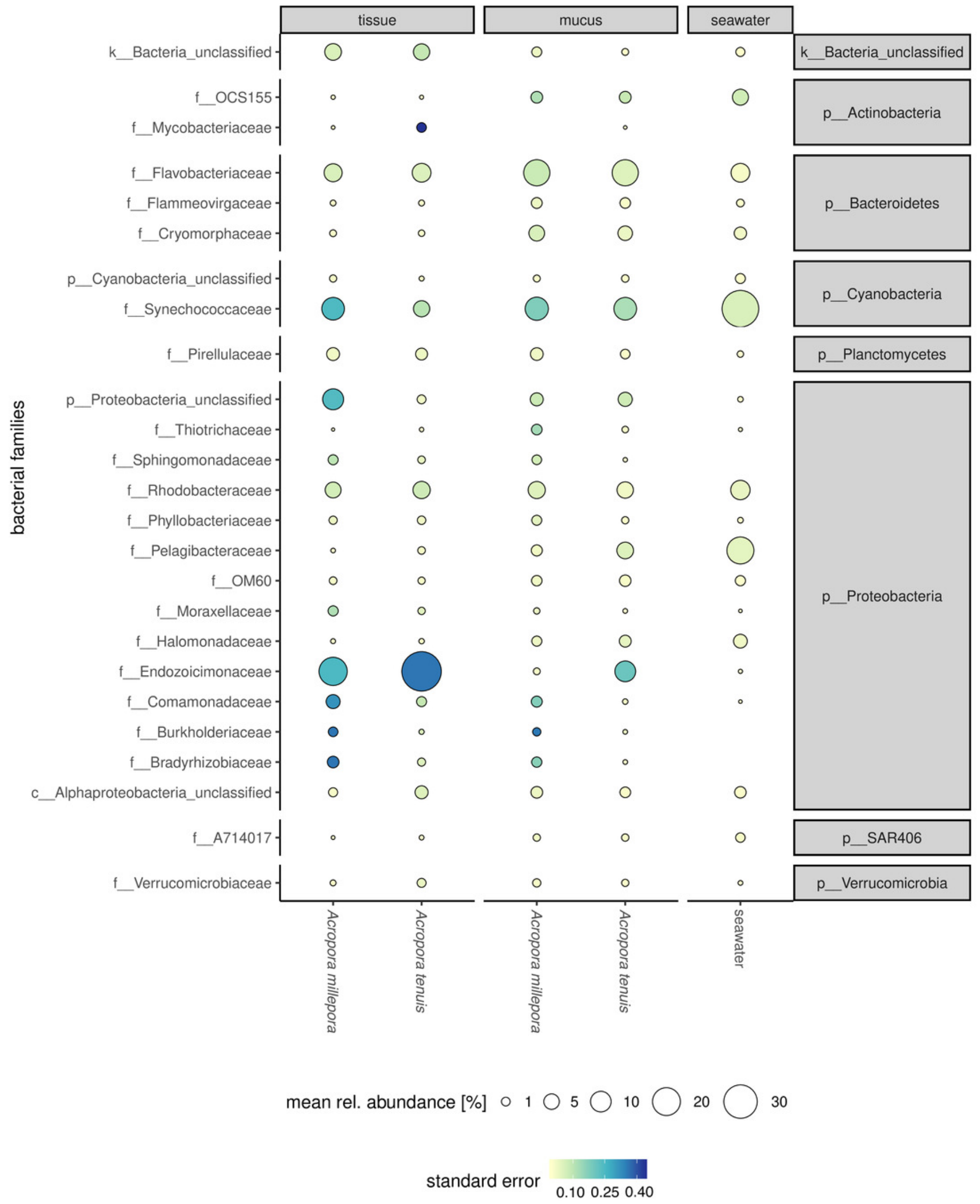


Figure 2

Alpha diversity measures of coral mucus, coral tissue, and seawater microbiomes.

(A) Venn diagram displaying the number of shared, unique, and ubiquitous zOTUs among mucus, tissue and seawater microbiomes. Two Acropora species ( $A$. tenuis and A. millepora) are pooled for the tissue and mucus microbiomes. (B) zOTU richness and (C) Shannon diversity index of microbiomes associated with tissue and mucus of $A$. millepora and $A$. tenuis, as well as with seawater.

A

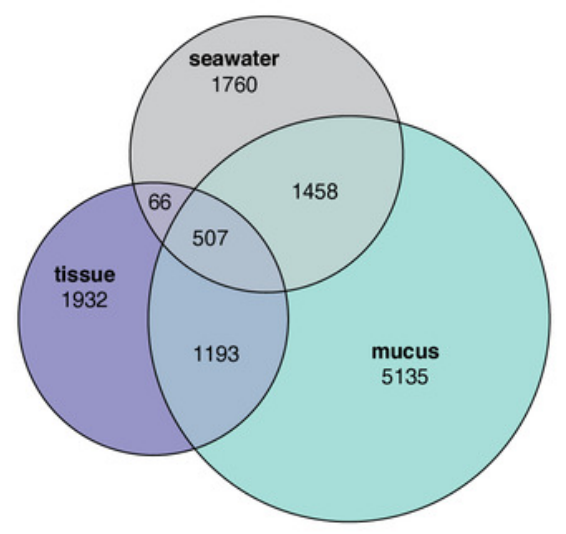

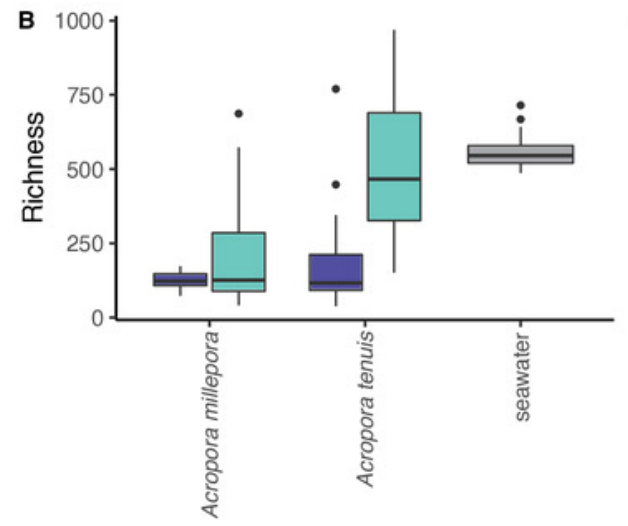

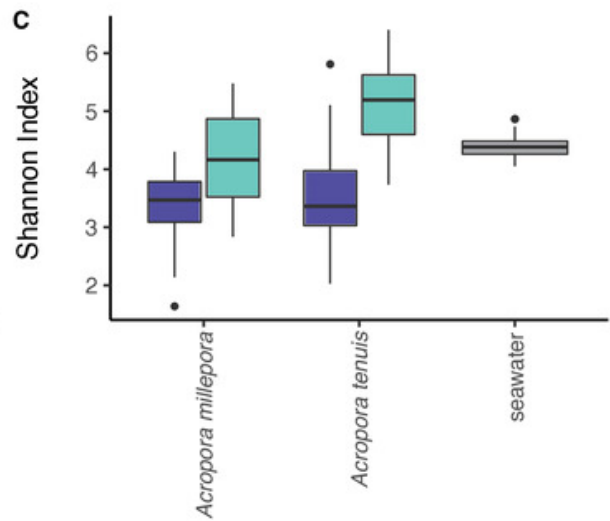

Compartment 追 tissue 追 mucus 追 seawater 


\section{Figure 3}

Compositional variability of microbiomes associated with distinct coral-compartments and the ambient seawater.

Two-dimensional non-metric multidimensional scaling (nMDS) ordination depicting variation in microbial community structure between coral compartments (mucus and tissue) of Acropora tenuis and Acropora millepora, and seawater samples. " $\mathrm{k}$ " is the number of dimensions.

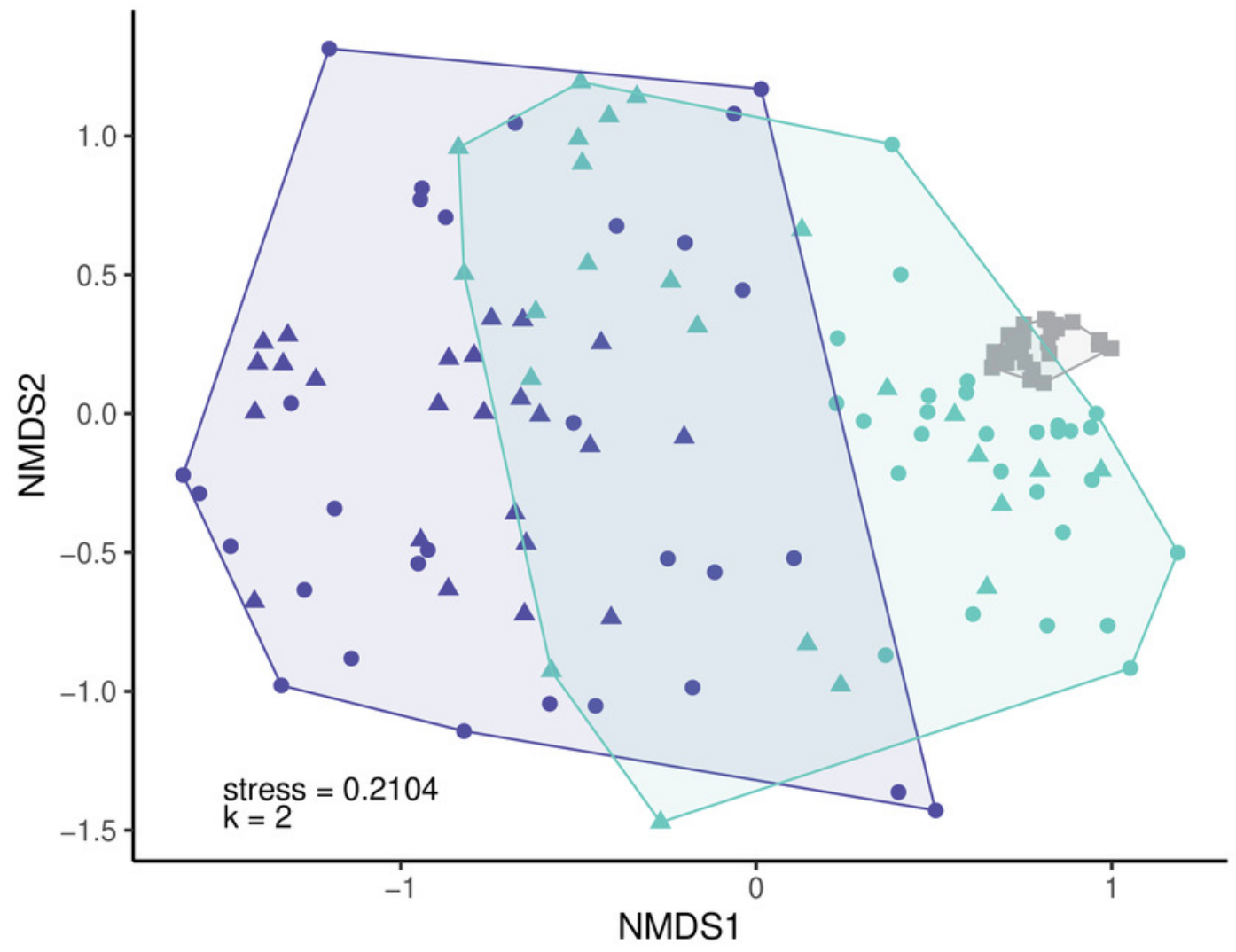

species

- Acropora tenuis

- Acropora millepora

- seawater

compartment

- tissue

- mucus

- seawater

NMDS1 


\section{Figure 4}

Environmental and physiological drivers of the Acropora tenuis and Acropora millepora microbiomes.

Distance-based redundancy analysis (db-RDA) of the relationship between environmental/physiological variables and the relative abundance of bacteria in (A) mucus and (B) tissue microbiome of $A$. millepora, and (C) mucus and (D) tissue microbiome of $A$. tenuis. Arrow length indicates the strength of the correlation between the variables and the samples (note only significant variables are shown). The selected variables explain a total of (A) $14.98 \%$, (B) $16.44 \%$, (C) $10.63 \%$ and (D) $10.97 \%$ of the observed variance, respectively. Environmental/physiological variables represented are the sum of nitrite and nitrate concentrations (NO2/NO3), particulate organic carbon (POC), total suspended solids (TSS), ammonium concentration $\left(\mathrm{NH}_{4}\right)$, chlorophyll a concentration (Chla) in seawater and Symbiodiniaceae density normalized to protein contents (Zoox/Pro) of coral tissue. 
mucus

A

A

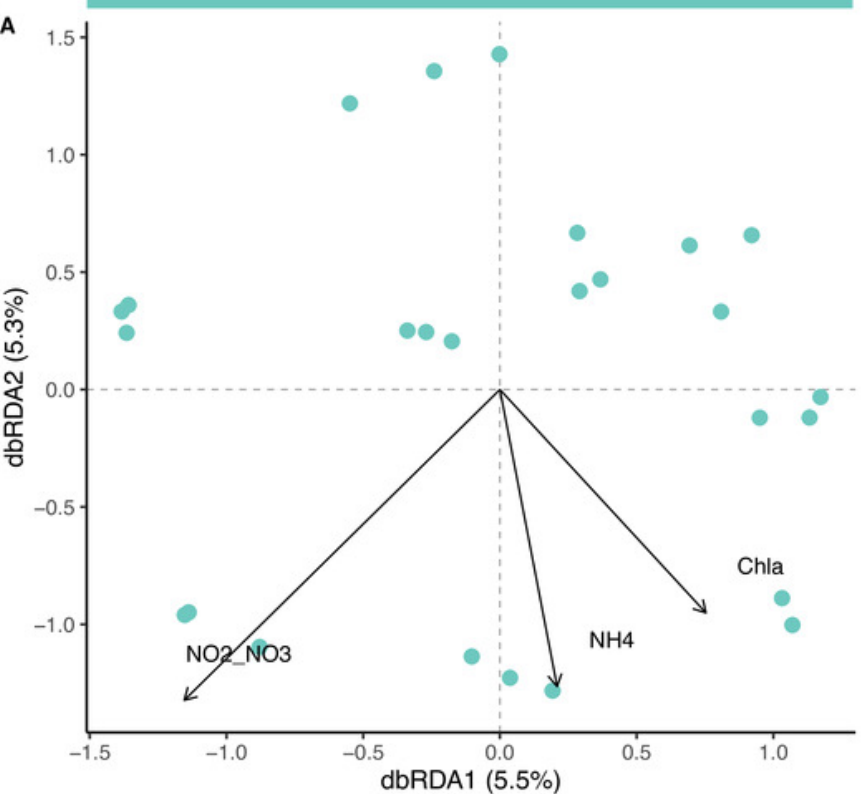

C

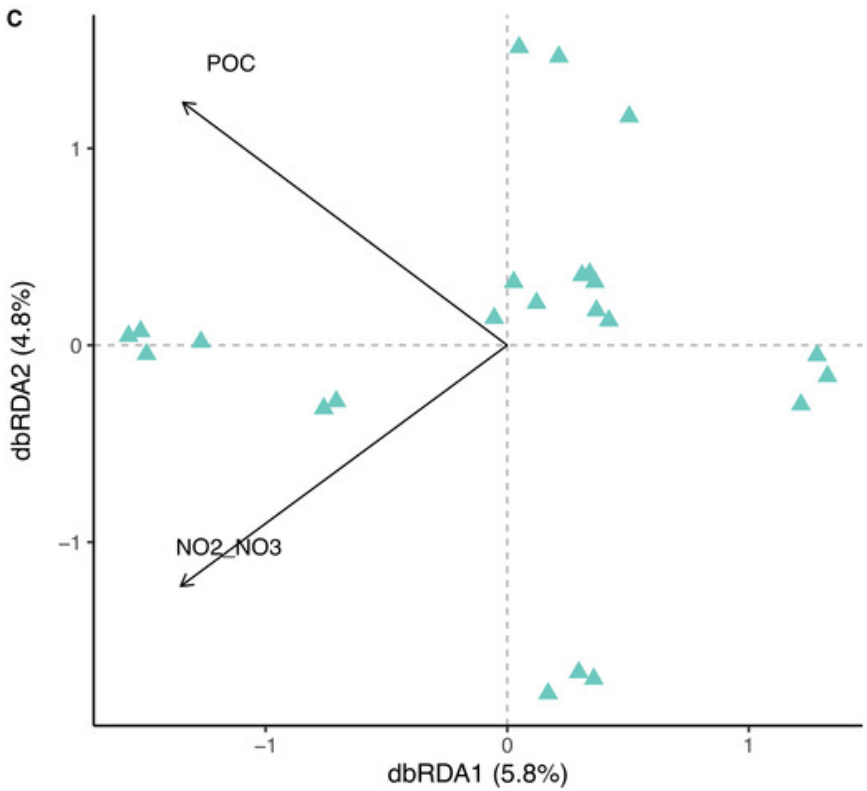

species • Acropora tenuis \Acropora millepora tissue

B

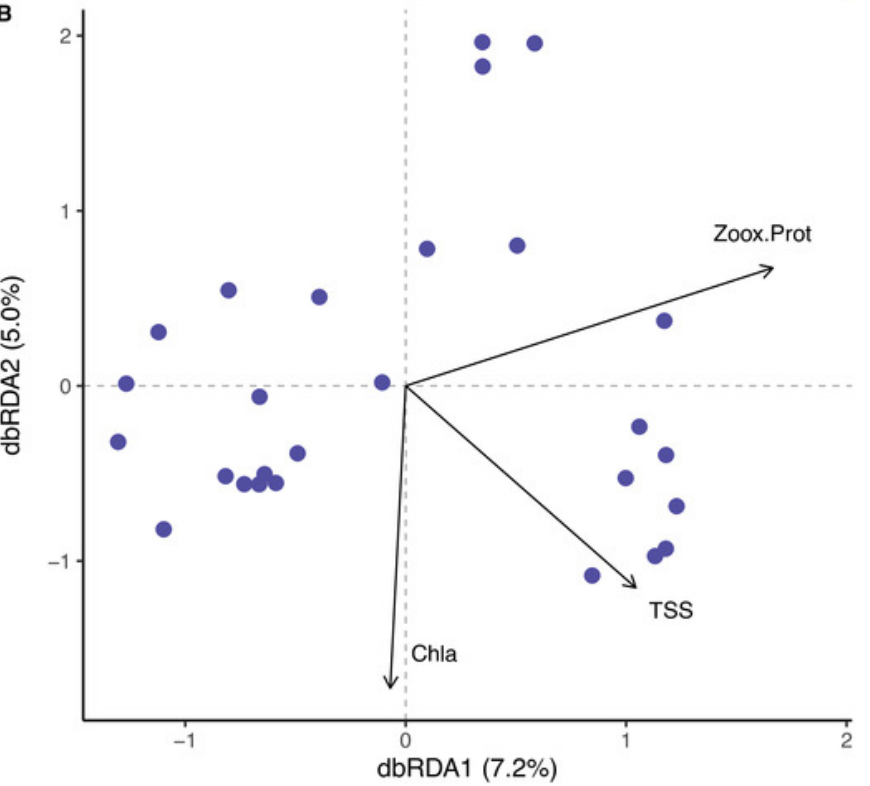

D

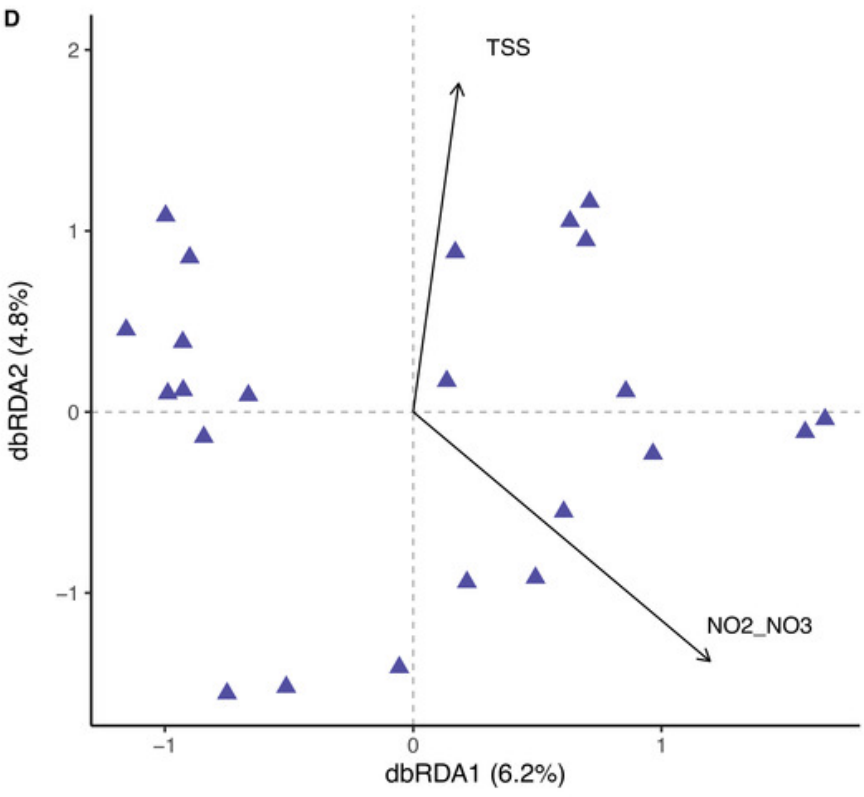

compartment $\bullet$ tissue $\bullet$ mucus 


\section{Figure 5}

Bacterial taxa significantly correlated with environmental and physiological variables.

Pearson's coefficient based correlation matrix between the 20 most abundant bacterial families and environmental/physiological variables having a significant effect on the microbiome associated to tissue and surface mucus of (A) Acropora millepora $\left(n_{\text {tissue }}=24\right.$, $\mathrm{n}_{\text {mucus }}=24$ ) and (B) Acropora tenuis ( $\mathrm{n}_{\text {tissue }}=30, \mathrm{n}_{\text {mucus }}=28$ ). Significant correlations indicated by asterisks at different levels of significance (* for $p<0.05$, ** for $p<0.01$, *** for $p<0.001$ ) after correction for multiple comparisons (using Benjamini-Hochberg correction). Environmental/physiological variables represented are the sum of nitrite and nitrate concentrations (NO2/NO3), particulate organic carbon (POC), total suspended solids (TSS), ammonium concentration $\left(\mathrm{NH}_{4}\right)$, chlorophyll a concentration (Chla) in seawater and Symbiodiniaceae density normalized to protein contents(Zoox/Pro) of coral tissue. 
A

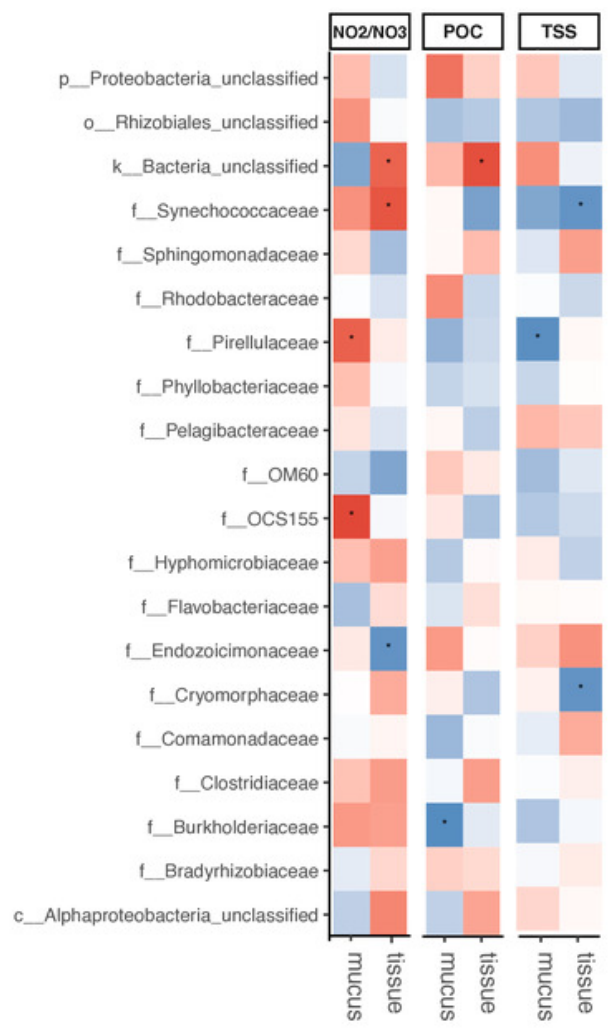

B

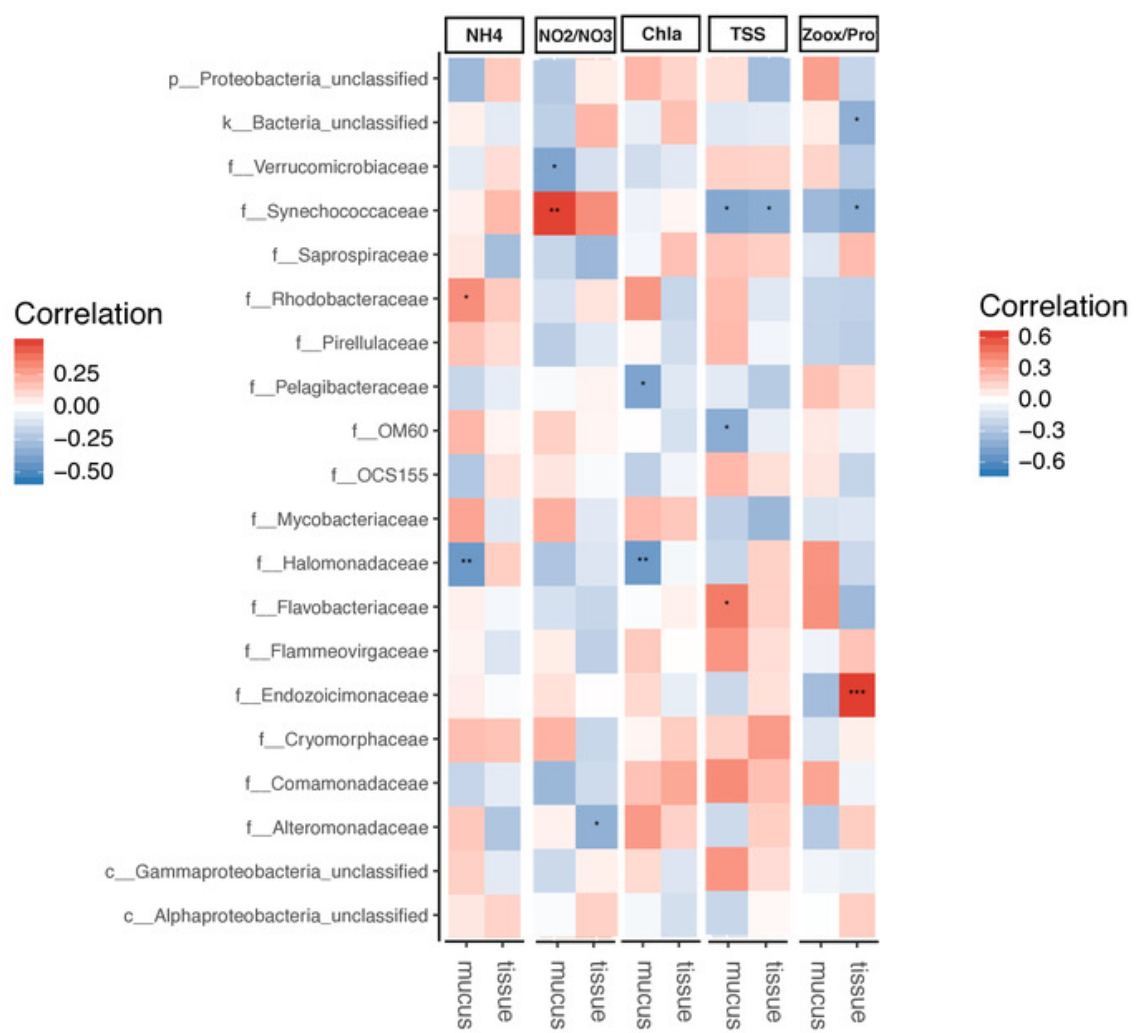

